Bundesgesundheitsbl 2012 $55: 1387-1400$

DOI 10.1007/s00103-012-1564-6

Online publiziert: 21. Oktober 2012

(c) Springer-Verlag 2012
I. Klare ${ }^{1} \cdot$ W. Witte ${ }^{1} \cdot$ C. Wendt ${ }^{2} \cdot$ G. Werner ${ }^{1}$

${ }^{1}$ Nationales Referenzzentrum für Staphylokokken und Enterokokken, Robert Koch-Institut, Wernigerode

2 Labor Dr. Limbach, Heidelberg

\section{Vancomycin-resistente Enterokokken (VRE)}

\section{Aktuelle Daten und Trends zur Resistenzentwicklung}

\section{Die Gattung Enterococcus}

Die grampositiven, katalasenegativen Enterokokken wurden früher zu den fäkalen Streptokokken gezählt, jedoch seit 1984 als eigene Gattung Enterococcus geführt $[1,2]$. Von den mittlerweile über 35 bekannten Enterokokkenspezies haben Enterococcus (E.) faecalis und E. faecium die größte klinische Bedeutung und gehören als Besiedler des Intestinaltraktes zur normalen Darmflora von Mensch und Tier. In Stuhlproben kommen E. faecalis mit etwa $10^{5}-10^{7} \mathrm{KBE} / \mathrm{g}$ (KBE, koloniebildende Einheiten) und E. faecium mit etwa $10^{4}-10^{5} \mathrm{KBE} / \mathrm{g}$ vor [3], die allerdings zusammen mit den Enterobacteriaceae nur rund $1 \%$ der Dickdarmflora des Menschen verkörpern. Gelegentlich treten Enterokokken in der Vaginalflora, in den Gallenwegen, selten jedoch im Oropharynx auf. Darüber hinaus sind diese Bakterien im Boden, im Wasser und vor allem im Abwasser, ferner auf Pflanzen sowie auf pflanzlichen und tierischen Lebensmitteln zu finden.

Enterokokken sind in der Lage, bei unterschiedlichen Umweltbedingungen zu wachsen, z. B. im pH-Bereich 4,6-9,9 (Optimum bei $\mathrm{pH} 7,5$ ), bei Temperaturen von $5-50^{\circ} \mathrm{C}$ (Optimum bei $42,7^{\circ} \mathrm{C}$; aber Resistenz gegen Hitzebehandlung bei $60^{\circ} \mathrm{C}$ für $30 \mathrm{~min}$ ) und bei $6,5 \%$ iger Kochsalzkonzentration. Sie sind unempfindlich gegen eine 40\%ige Gallesalzkonzentration und zeichnen sich durch un- vollständige Hämolyse ( $\alpha$-Hämolyse) aus $[3,4]$. Weiterhin sind diese fakultativ anaeroben Bakterien gegen Austrocknung resistent und überleben auf abiotischen Oberflächen. Diese Charakteristika sind unter anderem Grundlage diagnostischer Identifizierungsschemata und werden auch bei krankenhaushygienischen Präventionsmaßnahmen berücksichtigt.

Durch Enterokokken wird eine Reihe von Infektionen verursacht, z. B. Harnwegsinfektionen, Wundinfektionen (insbesondere im Abdominalbereich, oft auch polymikrobiell), Peritonitiden oder auch schwere Infektionen wie Bakteriämien/Septikämien und Endokarditiden. Die Enterokokkenseptikämien gelten als besonders schwerwiegend, ihre Gesamtmortalitätsraten werden mit $28-58 \%$ und die direkten Mortalitätsraten mit $31 \%$ angegeben $[5,6,7,8,9,10,11,12,13]$. Die genannten Infektionen können vor allem bei Früh- und Neugeborenen, bei älteren Personen sowie bei Patienten mit einem Grundleiden und/oder mit einer Immunsuppression auftreten. Gerade in den industriellen Ländern, in denen aufgrund des medizinischen Fortschritts immer mehr ältere Menschen leben (oft multimorbide Patienten) und gleichzeitig neue invasive medizinische Behandlungsmöglichkeiten existieren, steigt die Zahl von Risikopatienten für Enterokokkeninfektionen. Deutlich häufiger als Infektionen treten allerdings Kolonisierungen auf, wenngleich für Stammzelltransplantierte angegeben wurde, dass ca. ein
Drittel der VRE-kolonisierten Patienten eine Sepsis entwickelte [13].

Auch wenn Enterokokken lange Zeit als „bedingt pathogen“ eingeschätzt wurden, sind sie unter den durch Mikroorganismen verursachten Krankenhausinfektionen (nosokomiale Infektionen) die zweit- bis dritthäufigsten Erreger, vor allem bei katheterassoziierten Harnwegsinfektionen oder Bakteriämien.

E. faecalis ist für $60-95 \%$ und E. faecium für 5-40\% der durch Enterokokken verursachten Infektionen und Besiedlungen von Patienten in deutschen oder anderen europäischen Krankenhäusern verantwortlich. In den Antibiotikaresistenzstudien der Paul-Ehrlich-Gesellschaft für Chemotherapie e.V. (PEG) wurde gezeigt, dass sich der Anteil der E.-faecium-Isolate (bezogen auf alle untersuchten Enterokokkenstämme) in Krankenhäusern Mitteleuropas kontinuierlich erhöht hatte: 9,3\% (1998) $\rightarrow 15,7 \%$ $(2001) \rightarrow 24,4 \%$ (2004) $\rightarrow 33,9 \%$ (2007) $\rightarrow 41,4 \%$ (2010) ([14], PEG-Daten aus 2010: persönliche Mitteilung M. Kresken, PEG). Die Häufigkeit des Auftretens dieser beiden wichtigsten Enterokokkenspezies wird von der Art des jeweiligen Krankenhauses und seinen klinischen Disziplinen, vom jeweiligen Patientengut (s. oben genannte Patienten) sowie von dem im Krankenhaus bzw. in der jeweiligen Klinikabteilung bestehenden Antibiotikaselektionsdruck beeinflusst. Als Risikofaktoren für Infektionen oder Besiedlungen von Patienten durch Entero- 
kokken (und durch die in dieser Arbeit beschriebenen VRE) kommen eine vorherige Behandlung durch Antibiotika mit einer „Enterokokkenlücke“ (Präparate, die bei Enterokokken aufgrund ihrer natürlichen Resistenzen nicht wirken, z. B. alle Cephalosporine, s. unten) infrage. In diesem Zusammenhang kann auch die Behandlung von Clostridiumdifficile- oder anderen Anaerobierinfektionen mit Metronidazol oder anderen Antibiotika durch Unterdrücken der anaeroben Darmflora das Wachstum von Enterokokken begünstigen und ein $\mathrm{Ri}$ sikofaktor für nachfolgende Infektionen mit E. faecium sein $[15,16]$. Außerdem sind längere Krankenhausaufenthalte mit vielgestaltigen antibakteriellen Chemotherapien, schwere Grunderkrankungen sowie intraabdominal- oder Herz/ Thorax-chirurgische Eingriffe als Risikofaktoren für Enterokokken-/VRE-Infektionen zu nennen. Auch der Aufenthalt in spezifischen Krankenhauseinheiten (vor allem Hämatologie/Onkologie, Urologie/Nephrologie, Transplantationseinheiten, Neonatologie), Mängel in der Basishygiene, das medizinische Personal (inklusive Ärzte) als mögliche Überträger dieser Bakterien und der Kontakt eines Patienten zu anderen Enterokokken-/VRE-besiedelten oder -infizierten Patienten bzw. mit diesen Mikroorganismen kontaminierten medizinischen Geräten oder Oberflächen in der Patientenumgebung (als Folge der hohen Umweltpersistenz von Enterokokken) kommen als weitere Risikofaktoren für eine Besiedlung von Patienten mit diesen Erregern in Betracht.

\section{Antibiotikaresistenzen von Enterokokken}

Von großer Bedeutung ist die breite Vielfalt der nachfolgend aufgeführten natürlichen (intrinsischen) und erworbenen Antibiotikaresistenzen von Enterokokken, die die Therapiemöglichkeiten bei Infektionen mit diesen Erregern (insbesondere durch E. faecium) stark einschränken können [17].
Natürliche Resistenzen besitzen Enterokokken gegen folgende Antibiotika:

- alle Cephalosporine,

- semisynthetische Penicilline (z. B. Oxacillin, Flucloxacillin) und Monobactame (Aztreonam),

- Polymyxine,

- Lincosamide,

- Streptogramine (z. B. Quinupristin/ Dalfopristin: nur E. faecalis),

- Mupirocin (nur E. faecalis),

- Aminoglycoside (Low-level-Resistenzen),

- Vancomycin (Low-level-Resistenzen in E. gallinarum und E. casseliflavus).

Erworbene Resistenzen können bei Enterokokken zusätzlich vorliegen gegen:

- Ampicillin (meist E. faecium; sehr selten: E. faecalis),

- Makrolide,

- Aminoglycoside (High-level-Resistenzen),

- Chloramphenicol,

- Fluorchinolone (Hochresistenz bei Hospital-assoziierten E.-faeciumStämmen [18]),

- Streptogramine (Quinupristin/Dalfopristin bei E. faecium),

- Tetracycline inklusive der neuen Glycylcycline (Tigecyclin),

- Glycopeptide [meist E. faecium, sehr selten in E. faecalis $(<1 \%)]$,

- Oxazolidinone (Linezolid).

Enterokokkeninfektionen werden üblicherweise mit Ampicillin, Amoxycillin, Acylureidopenicillinen oder ähnlichen Penicillinen behandelt, bei schweren Infektionen auch in Kombination mit Aminoglycosiden (Gentamicin, Streptomycin), um einen synergistischen und bakteriziden Effekt zu erzielen. Liegt jedoch bei dieser geplanten Therapie bereits eine Resistenz gegen einen Kombinationspartner vor (z. B. Ampicillin-Resistenz oder/und Aminoglycosid-Hochresistenz), kommt es zum Versagen des synergistischen Effektes. In diesem Fall wären Glycopeptide (Vancomycin, Teicoplanin) die Antibiotika der Wahl. Tritt dann eine Resistenz gegen Glycopeptide auf, verringern sich die therapeutischen Möglichkeiten dramatisch. In diesem Fall würden noch Quinupristin/Dalfopristin, Linezolid, Tigecyclin und Daptomycin als Therapeu- tika bereitstehen. Quinupristin/Dalfopristin wirkt allerdings nur gegen $E$. faecium und nicht gegen E. faecalis; außerdem ist dieses Präparat in Deutschland nicht mehr im Handel, in den USA wird es von Monarch Pharmaceuticals Inc. angeboten. Daptomycin wird als Therapeutikum bei Enterokokkeninfektionen bezüglich seiner In-vivo-Wirksamkeit zum Teil unterschiedlich bewertet (hohe Eiweißbindung), und bei EUCAST (European Committee on Antimicrobial Susceptibility Testing, [19]) sind für dieses Antibiotikum auch keine klinischen Grenzwerte, sondern nur ein mikrobiologischer Grenzwert des Wildtyps von $\leq 4 \mathrm{mg} / \mathrm{l}$ angegeben. Allerdings verweisen zahlreiche Arbeiten auf die Wirksamkeit von Daptomycin auch bei Enterokokkeninfektionen (Übersicht bei [20]). Linezolid und Tigecyclin sind bei Enterokokken sehr wirksame Präparate und Resistenzen gegen diese bisher noch selten bis sehr selten, können jedoch unter der Therapie mit ihnen auftreten. Linezolid-resistente Mutanten des betreffenden Enterokokkenstammes wurden teilweise schon nach wenigen Therapietagen isoliert [21, 22, 23].

Da bei klinischen E.-faecium-Isolaten in Deutschland $94-95 \%$ der Isolate resistent gegen Amoxicillin/Ampicillin sind (im Gegensatz zu E. faecalis: $\leq 1 \%$ ) und auch bei ambulanten E.-faecium-Isolaten bereits eine Resistenzhäufigkeit von 68$82 \%$ gegen Amoxicillin/Ampicillin vorliegt [24], kommt der Überwachung der in erster Linie bei E. faecium vorkommenden übertragbaren Glycopeptidresistenztypen VanA und VanB (s. unten) eine entscheidende Bedeutung zu.

\section{Zur Vancomycin-Resistenz der Enterokokken}

Glycopeptide wie Vancomycin und Teicoplanin hemmen die Zellwandbiosynthese von Enterokokken (und anderen grampositiven Bakterien), indem sie am terminalen D-Alanin-D-Alanin des Pentapeptids, das für die Quervernetzung der langen (N-Acetyl-Glycosamin-N-AcetylMuraminsäure $)_{n}$-Ketten verantwortlich ist, binden. Dabei kommt es zu einer sterischen Abschirmung des Pentapeptids für die aufzubauende Quervernetzung 
und zur Behinderung der nachfolgenden Transglycosilierungsreaktion (Folge: nicht intakter Mureinsacculus; Zelltod $[25,26,27])$. Vancomycin-resistente Enterokokkenstämme haben nun das terminale D-Alanin-D-Alanin dieses Pentapeptids durch D-Alanin-D-Lactat (z. B. bei VanA und VanB in E. faecium/E. faecalis und anderen Enterokokkenspezies) oder durch D-Alanin-D-Serin (z. B. bei $\mathrm{VanC}_{1} / \mathrm{VanC}_{2}$ in E. gallinarum/E. casseliflavus und in anderen VancomycinResistenztypen) ausgetauscht (• Tab. 1, [28]). Diese Modifikation führt beispielsweise beim VanA-Typ zu einer bis zu 1000-fach gesunkenen Bindungsfähigkeit von Vancomycin an das Pentapeptid und erklärt die Glycopeptidresistenz des entsprechenden Enterokokkenstammes mit meist sehr hohen MHK-Werten für Vancomycin (8-1000 mg/l) bei gleichzeitiger Kreuzresistenz zu Teicoplanin [MHKWerte: (4-) 16-512 mg/l]. Allerdings gibt es auch seltene vanA-positive E.-faeciumIsolate, die MHK-Werte für Vancomycin im resistenten Bereich ( $>4 \mathrm{mg} / \mathrm{l})$, jedoch MHK-Werte für Teicoplanin von $2 \mathrm{mg} / \mathrm{l}$ („empfindlich“) aufweisen. Solche vanApositiven (!), aber Teicoplanin-“empfindlichen" Stämme, die auch in dem von den Krankenhäusern und klinisch mikrobiologischen Laboren an das RKI in Wernigerode eingesandten Stammmaterial auftraten, sollten bei der Befundung der Ergebnisse sicherheitshalber als potenziell Teicoplanin-resistent betrachtet werden.

Beim VanB-Typ liegt bei Enterokokken nur eine Resistenz gegen Vancomycin vor, gegen Teicoplanin sind sie empfindlich. Allerdings kann die VancomycinResistenz der Enterokokkenisolate unterschiedlich stark exprimiert sein, was sich in MHK-Werten von $\leq 4$ bis $1000 \mathrm{mg} / \mathrm{l}$ niederschlägt. Unter den an das RKI in Wernigerode eingesandten Enterokokkenstämmen existieren sogar E.-faecium-Isolate mit Vancomycin-MHK-Werten von 2 oder gar $1 \mathrm{mg} / \mathrm{l}$ („empfindlich“), die aber in der PCR vanB-positiv sind. Das heißt, ein bestimmter Anteil der VanB-Stämme von E. faecium wird ohne Nachweis des vanB-Gens im klinisch mikrobiologischen Laboratorium nicht erfasst. Man sollte daher auch solche phänotypisch „Vancomycin-empfindlichen“, aber vanB-positiven E.-faecium-Stäm-

Bundesgesundheitsbl 2012 ·55:1387-1400 DOI 10.1007/s00103-012-1564-6

C Springer-Verlag 2012

\section{Klare $\cdot$ W. Witte $\cdot$ C. Wendt $\cdot$ G. Werner \\ Vancomycin-resistente Enterokokken (VRE). Aktuelle Daten und Trends zur Resistenzentwicklung}

\section{Zusammenfassung}

Enterokokken (vorrangig E. faecalis, E. faecium) sind bedeutende nosokomiale Erreger, die vor allem bei älteren und/oder immunsupprimierten Patienten auftreten. Sie besitzen ein breites Spektrum an intrinsischen und erworbenen Antibiotikaresistenzen, von denen die übertragbaren Glycopeptidresistenzgenotypen vanA und vanB in Vancomycin-resistenten Enterokokken (VRE; Reservoir: E. faecium) sowie Resistenzen gegen Reserveantibiotika (Linezolid, Tigecyclin) von besonderem Interesse sind. Außerdem zeichnen sich Enterokokken (einschließlich VRE) durch ihre leichte Übertragbarkeit aus und können somit als Indikatorkeim für eine nosokomiale Ausbreitung angesehen werden, wobei Kolonisationen deutlich häufiger auftreten als Infektionen. Seit einigen Jahren liegen die Resistenzhäufigkeiten gegen Vancomycin bei klinischen E.-faecium-Isolaten bei 8-15\% auf einem konstanten Niveau (aber mit lokalen und regionalen Schwankungen) und zeigen für Teicoplanin einen leicht rückläufigen Trend. Dies korreliert mit der Verbreitung Hospital-assoziierter vanA- und in den letzten Jahren vanB-positiver E.-faeciumStämme (Letztere assoziiert mit TeicoplaninEmpfindlichkeit). Die Ursachen für das deutlich zunehmende Auftreten von VanB-E.-faecium-Stämmen sind offenbar multifaktoriell: durch therapeutische Faktoren verursacht (gestiegener Verbrauch an Enterokokken-/ VRE-selektierenden Antibiotika in der Vergangenheit) und methodisch bedingt (EUCAST-gesenkte Glycopeptid-MHK-Grenzwerte für Enterokokken; häufigeres und verbessertes VRE-Screening; molekulare diagnostische Verfahren).

\section{Schlüsselwörter}

Enterokokken · Hospital-assoziierte Stämme · Vancomycin-Resistenz - vanB E. faecium . Antibiotikaselektionsdruck

\section{Vancomycin-resistant enterococci (VRE). Recent results and trends in development of antibiotic resistance}

\section{Abstract}

Enterococci (mainly E. faecalis, E. faecium) are important nosocomial pathogens predominantly affecting older and/or immunocompromised patients. The bacteria possess a broad spectrum of intrinsic and acquired antibiotic resistance properties. Among these, the transferrable glycopeptide resistance of the vanA and vanB genotypes in vancomycin-resistant enterococci (VRE; reservoir: E. faecium) as well as resistance to last resort antibiotics (e.g. linezolid and tigecycline) are of special concern. Enterococci (including VRE) are easily transferred in hospitals; however, colonizations are far more frequent than infections. Resistance frequencies for vancomycin in clinical $E$. faecium isolates have remained at a relatively constant level of $8-15 \%$ (but with local or regional variations) in recent years whereas frequencies for teicoplanin resistance have shown a slight de- crease. Glycopeptide resistance trends correlate with a spread of hospital-associated $E$. faecium strains carrying the vanA and, with rising frequency in recent years, the van $B$ gene cluster, the latter being associated with teicoplanin susceptibility. This increased occurrence of vanB-positive E. faecium strains may be caused by an increased use of antibiotics selecting enterococci and VRE as well as due to methodological reasons (e.g. reduced EUCAST MIC-breakpoints for glycopeptides; increased use and sensitive performance of chromogenic VRE agars; increased use of molecular diagnostic assays).

\section{Keywords}

Enterococci · Hospital-associated strains . Vancomycin resistance $\cdot$ vanB E. faecium . Antibiotic selective pressure me sicherheitshalber immer als potenziell Vancomycin-resistent setzen. Die zumeist auf mobilen Elementen (Plasmiden, Transposons) lokalisierten vanAbzw. vanB-Gencluster sind innerhalb der
Enterokokken effektiv übertragbar, können aber auch andere grampositive Erreger erreichen (z. B. vanA bei Methicillin-resistenten Staphylococcus aureus oder vanB bei Streptococcus bovis [29, 30, 
Tab. 1 Typen der erworbenen Vancomycin-Resistenz bei Enterokokken [28]

\begin{tabular}{|c|c|c|c|c|c|c|c|}
\hline $\begin{array}{l}\text { Resistenz- } \\
\text { Phänotyp }\end{array}$ & $\begin{array}{l}\text { MHK }_{\text {Vancomycin }} \\
(\mathrm{mg} / \mathrm{l})\end{array}$ & $\begin{array}{l}\mathrm{MHK}_{\text {Teicoplanin }} \\
(\mathrm{mg} / \mathrm{l})\end{array}$ & Expression & Ligase & $\begin{array}{l}\text { Lokali- } \\
\text { sation }\end{array}$ & $\begin{array}{l}\text { Konjugativ } \\
\text { übertragbar }\end{array}$ & Verbreitung in Enterokokkenarten \\
\hline $\operatorname{Van} A^{a}$ & $(2-) 8-1000$ & (4-) 16-512 & Induzierbar & D-Ala-D-Lac & $\mathrm{P} / \mathrm{C}$ & $+/-$ & $\begin{array}{l}\text { E. faecium, E. faecalis, E. durans, E. hirae, E. raf- } \\
\text { finosus, E. avium, E. mundtii, E. gallinarum }{ }^{\text {b }} \text {, } \\
\text { E. casseliflavus }^{\text {b }}\end{array}$ \\
\hline $\operatorname{VanB}{ }^{a}$ & $(1-)$ 4-32 (-1000) & $0,5-1$ & Induzierbar & D-Ala-D-Lac & $\mathrm{C} / \mathrm{P}$ & $+/-$ & $\begin{array}{l}\text { E. faecium, E. faecalis, E. durans, E. gallina- } \\
\text { rum }^{\text {b }} \text {, E. casseliflavus }\end{array}$ \\
\hline $\operatorname{VanD}^{c}$ & $16-512$ & $0,5-64$ & Konstitutiv & D-Ala-D-Lac & C & - & $\begin{array}{l}\text { E. faecium, E. faecalis, E. raffinosus, E. galli- } \\
\text { narum }^{\text {b }}\end{array}$ \\
\hline VanE & $8-32$ & 0,5 & Induzierbar & D-Ala-D-Ser & C & - & E. faecalis \\
\hline $\operatorname{VanGc}$ & 16 & 0,5 & Induzierbar & D-Ala-D-Ser & C & + & E. faecalis \\
\hline VanL & 8 & $\mathrm{~S}$ & Induzierbar & D-Ala-D-Ser & C? & - & E. faecalis \\
\hline VanM & $>256$ & $0,75 / 96^{d}$ & Induzierbar & D-Ala-D-Lac & $\mathrm{P}$ & + & E. faecium \\
\hline VanNe & 16 & $0,5-1$ & Konstitutiv & D-Ala-D-Ser & $\mathrm{P}$ & $+1-$ & E. faecium \\
\hline \multicolumn{8}{|c|}{ 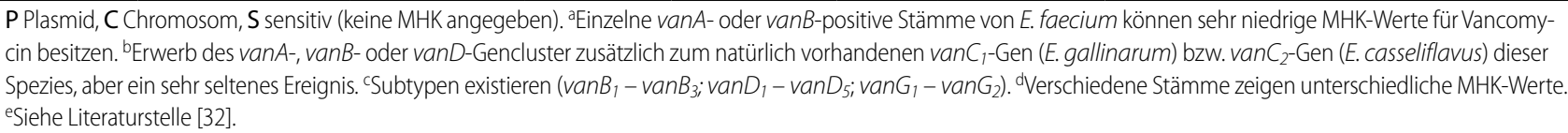 } \\
\hline
\end{tabular}

31]) und stellen damit eine zusätzliche Bedrohung für Krankenhauspatienten dar. Dennoch ist das Reservoir der transferablen vanA- und vanB-kodierten Glycopeptidresistenz in E. faecium zu sehen; bei $E$. faecalis treten diese Resistenzen in unter $1 \%$ der Isolate auf. Während etwa bis 2003/2004 VanB-E.-faecium-Stämme im klinischen Alltag eher selten waren, hat die Häufigkeit ihres Auftretens in den letzten Jahren stark zugenommen. Innerhalb der VRE-Einsendungen an das RKI in Wernigerode finden sich derzeit beide übertragbaren van-Typen nahezu gleich häufig. Darauf wird in einem eigenen Abschnitt dieses VRE-Beitrages eingegangen.

Bei den Enterokokken mit erworbenen Glycopeptidresistenzen sind mittlerweile 6 weitere Resistenztypen gefunden worden (VanD, VanE, VanG, VanL, VanM, VanN), bei denen das terminale D-Ala-D-Ala durch D-Ala-D-Lac oder D-Ala-D-Ser ausgetauscht ist $[28,32]$. Bei Vorliegen von D-Ala-D-Lac (VanD, VanM) kann dies auch zur Kreuzresistenz gegen Vancomycin und Teicoplanin führen, bei den anderen erworbenen Resistenztypen mit D-Ala-D-Ser endenden Pentapeptiden nur zur Vancomycin-Resistenz bei gleichzeitiger Teicoplanin-Empfindlichkeit (VanE, VanG, VanL, VanN; s. - Tab. 1). Diese 6 neuen, teilweise übertragbaren Glycopeptidresistenztypen haben aber (bisher) keine klinische Bedeutung.
Bei den natürlichen (intrinsischen) VanC $_{\mathbf{1}^{-}}$(E. gallinarum) bzw. VanC $\mathbf{C}_{2}-\mathbf{T y}-$ pen (E. casseliflavus) mit ihrem terminalen D-Alanin-D-Serin ist die Bindungsfähigkeit des Vancomycins an das Pentapeptidende längst nicht so effektiv reduziert wie beim D-Alanin-D-Lactat der VanA- oder VanB-Stämme von E. faecium oder E. faecalis. Dies führt daher auch nur zu Low-level-Resistenzen gegen Vancomycin mit MHK-Werten von $8(-32)$ $\mathrm{mg} / \mathrm{l}$ bei E. gallinarum und von nur (1-) 2-4 mg/l bei E. casseliflavus bei gleichzeitiger Teicoplanin-Empfindlichkeit beider Spezies.

Diese als Spezieseigenschaften anzusehenden natürlichen Low-level-Vancomycin-Resistenzen $\mathrm{VanC}_{1}$ (E. gallinarum) und $\mathrm{VanC}_{2}$ (E. casseliflavus) sind chromosomal kodiert und nicht übertragbar. Solche Isolate haben klinisch gesehen (im Gegensatz zu den in $\bullet$ Tab. 1 dargestellten erworbenen Resistenztypen VanA und VanB) nur eine geringe Bedeutung [33, 34], und Patienten, die mit nur van $C_{1}$ - oder $\operatorname{van}_{2}$-Genclustertragenden E.-gallinarum- bzw. E.-casseliflavus-Stämmen besiedelt/infiziert sind, brauchen auch nicht isoliert werden [35]. Der Nachweis der van $C_{1}$ - bzw. van $C_{2}$-Resistenzgene mittels PCR kann zusätzlich als molekulares Diagnostikmerkmal zur Identifizierung verwendet werden. Molekulare Untersuchungen haben außerdem gezeigt, dass E. casseliflavus und die früher davon unterschiedene Spezies E. fla- vescens die gleiche Spezies E. casseliflavus darstellen [36]).

Aufgrund der manchmal nicht eindeutigen oder widersprüchlichen Vancomycin-Resistenz-Phänotypen ist eine Bestimmung der zugrunde liegenden Resistenzgene mittels DNS-basierter Verfahren von wichtigem diagnostischem Wert, unter anderem auch für eine Bestätigung der vanC-spezifischen Spezies E. gallinarum und E. casseliflavus. Hierzu stehen verschiedene PCR, Real-time-PCR und hybridisierungsbasierte Assays zur Verfügung, die häufig parallel (als Multiplex-PCR) mehrere Resistenzgene und speziesspezifische Marker erfassen. „Inhouse-Lösungen“" und kommerziell angebotene Systeme sind hier gleichwertig [37, 38], wobei die kommerziellen Systeme ausschließlich die häufigsten Typen van $A, \operatorname{van} B$ und teilweise van $C$ erfassen. Bei Vancomycin-Resistenz und keinem nachweisbaren van $A$-, vanB- oder van $C$ Gencluster ist empfohlen, diese Isolate zur Überprüfung an ein Referenzlabor zu schicken. Nach unserem Kenntnisstand ist in Deutschland bisher der vanD-Typ einmal in 2 Isolaten von E. faecium nachgewiesen worden [39]. Eine weitere Möglichkeit zur Identifizierung von Enterokokken mit molekularen Methoden wäre die PCR der 16S-rRNA-Sequenzen [40, 41]. Diese molekularen Methoden stellen wertvolle Ergänzungen zu biochemischen Identifizierungstests dar (z. B. „Bunte Reihe“ im Mikromaßstab oder 


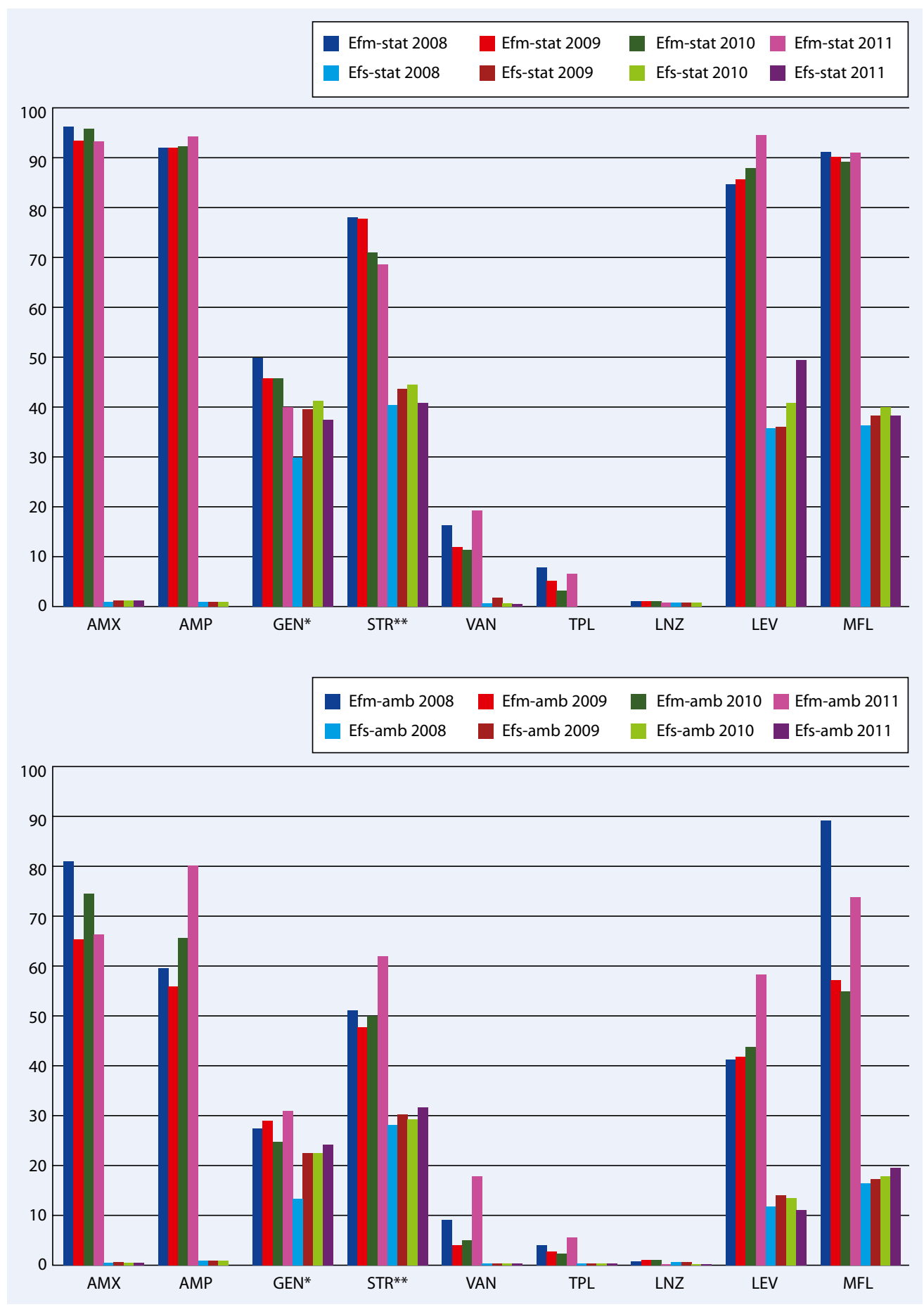

Abb. 14 Häufigkeiten von Resistenzen (\%) bei E.-faecium- und E.faecalis-Isolaten jeweils aus dem stationären Bereich von Krankenhäusern (oben) und aus dem ambulanten Bereich (unten) in Deutschland 2008 bis 2011 gegen 9 Antibiotika (ARS-Daten, s. https://ars.rki.de). Efm E. faecium, Efs E. faecalis, amb ambulanter Bereich, stat stationärer Bereich, AMX Amoxicillin, AMP Ampicillin, GEN Gentamicin ( ${ }^{*}$ nur Highlevel-Resistenz mit MHK-Werten von $>500 \mathrm{mg} / \mathrm{l}$ angegeben), STR Streptomycin (** nur High-level-Resistenz mit MHK-Werten von $>1000 \mathrm{mg} / \mathrm{l}$ angegeben), VAN Vancomycin, TPL Teicoplanin, LNZ Linezolid, LEV Levofloxacin, MFL Moxifloxacin. Grundlage dieser prozentualen Resistenzhäufigkeiten sind die bei ARS angegebenen sehr unterschiedlichen Anzahlen der ausgewerteten Isolate bei den einzelnen Antibiotika im Zeitraum 2008 bis 2011: bei Efm-amb zwischen 58 und 408 Isolate, bei Efsamb zwischen 1410 und 9171 Isolate, bei Efm-stat zwischen 175 und 4450 Isolate und bei Efs-stat zwischen 742 und 6646 Isolate (Einzelheiten s. unter https:// ars.rki.de)
Einsatz von Automaten mit Identifizierungs- und Resistenzbestimmungssystemen).

In sehr seltenen Fällen kann es E.-gallinarum- und E.-casseliflavus-Isolate geben, die neben ihrer natürlichen $\operatorname{van}_{1^{-}}$ bzw. van $C_{2}$-vermittelten Low-level-Vancomycin-Resistenz zusätzlich ein vanA-, vanB- (oder auch äußerst selten auch ein vanD-) Gencluster besitzen ( $\bullet$ Tab. 1), das jeweils auch parallel zum van $_{1^{-}}$oder van $C_{2}$-Gen in der PCR nachweisbar ist $[42,43,44]$. Solche $\left(\right.$ van $_{1} /$ van $C_{2}+v a-$ $n A)$ - oder $\left(v a n C_{1} / v a n C_{2}+v a n B\right)-S t a ̈ m-$ me treten dann phänotypisch wie VanAoder VanB-Isolate von E. faecium in Erscheinung.

Wie auch anhand der an das RKI in Wernigerode eingesandten VRE-Stämme zu sehen war, kann es bei Laborauto- maten zur bakteriellen Identifizierung und Resistenzbestimmung gelegentlich vorkommen, dass ein Stamm als „Vancomycin- (ggf. und Teicoplanin)-hochresistenter E. casseliflavus "diagnostiziert wird. Dies könnte dann theoretisch ein solches zuvor beschriebenes $v_{a n} C_{2}$-Isolat mit zusätzlichem vanA- oder vanB-Gencluster sein, jedoch ist die Wahrscheinlichkeit höher, dass es sich um einen fehl- 


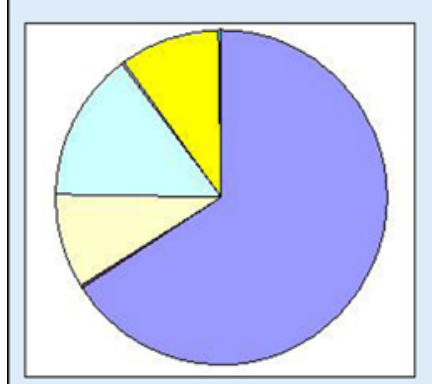

PEG-1998: E. faecalis ( $n=757), A: 0,9 \%$

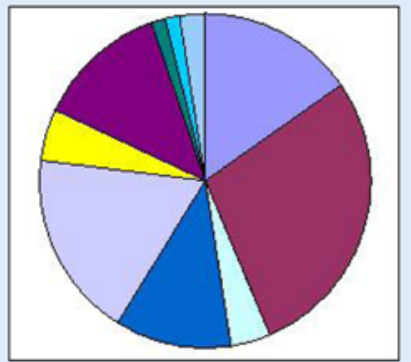

PEG-1998: E. faecium ( $n=78$ ), A: 75,6\%

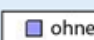

a $A+V$

$\square \mathrm{A}+\mathrm{S}+\mathrm{V}$

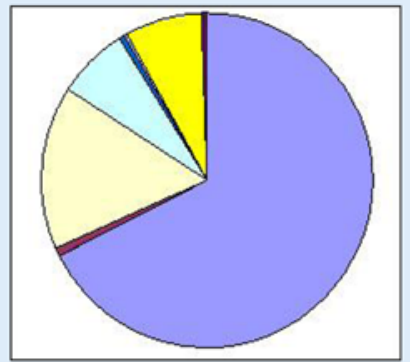

PEG-2001: E. faecalis ( $n=590), A: 2,0 \%$

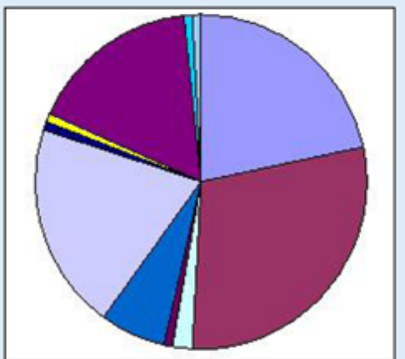

PEG-2001: E. faecium ( $n=110), A: 74,6 \%$

$\square \mathrm{G} \quad \square \mathrm{S}$

$\square \mathrm{G}+\mathrm{S} \quad \square \mathrm{G}+\mathrm{T}$

$\square \mathrm{A}+\mathrm{G}+\mathrm{V}+\mathrm{T}$

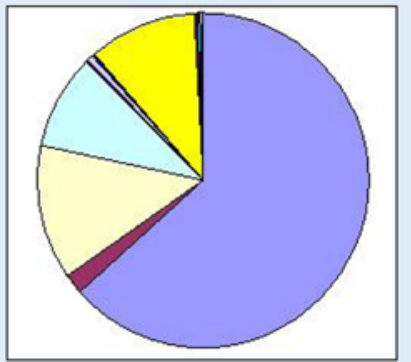

PEG-2004: E. faecalis ( $n=599), A: 3,3 \%$

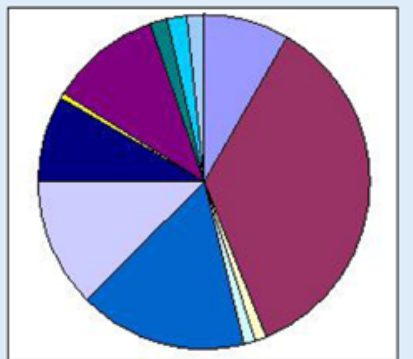

PEG-2004: E. faecium ( $n=193), A: 89,2 \%$

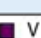

a $\mathrm{V}$

a+G+S

a $A+G+S+V$

a $A+V+T$

$\mathrm{A}+\mathrm{G}+\mathrm{S}+\mathrm{V}+\mathrm{T}$

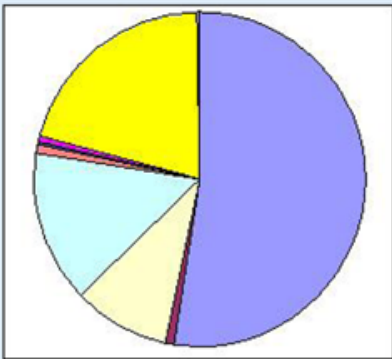

PEG-2007: E. faecalis $(n=488), A: 1,6 \%$

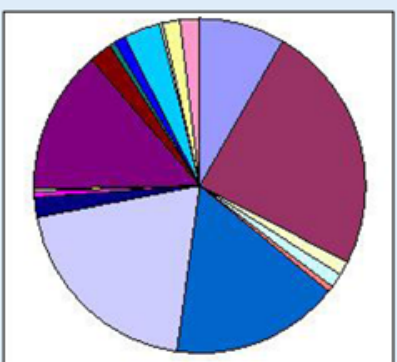

PEG-2007: E. faecium ( $n=250), A: 87,6 \%$

$\square A+G \quad \square A+S$

Abb. $2 \Delta$ Häufigkeiten von Einzel- und Multiresistenzen (\%) gegen verschiedene Antibiotika bei E.-faecalis- (oben) bzw. E.-faecium-Isolaten (unten) aus den Resistenzstudien der Paul-Ehrlich-Gesellschaft für Chemotherapie e.V. (PEG) der Jahre 1998, 2001, 2004 und 2007. Resistenzen gegen A Ampicillin, G Gentamicin (Hochresistenz), S Streptomycin (Hochresistenz), $\checkmark$ Vancomycin, TTeicoplanin; ohne keine dieser Antibiotika. Die oben genannten, zeilenweise je von links nach rechts angeordneten Farbsymbole der Einzel- und Multiresistenzen entsprechen der in den Kreisdiagrammen jeweils oben mit den empfindlichen Isolaten (ohne Resistenzen) beginnend und im Uhrzeigersinn aufgetragenen Reihenfolge dieser (Multi-)Resistenzen. Zusätzlich sind unter jedem Kreisdiagramm die Häufigkeiten der Ampicillin-Resistenz (A, Gesamtresistenz von Ampicillin aus Einzel- und Multiresistenzen berechnet) für E. faecalis (oben) bzw. E. faecium (unten) in den einzelnen Jahren der PEG-Resistenzstudien angegeben

identifizierten Vancomycin- (und Teicoplanin-)-hochresistenten E. faecium handelt.

Hier helfen 2 einfache Tests zur eindeutigen Identifizierung weiter:

- Nachweis der Beweglichkeit von E. casseliflavus und E. gallinarum: mittels Motility GI-Medium (Difco, Cat.-No. 286910. Semisolid gelatin heart infusion medium for demonstrating microorganism motility). E. casseliflavus und E. gallinarum sind beweglich, und es zeigt sich nach Beimpfung und Übernachtbebrütung des Mediums eine diffuse Wachstumszone rings um den senkrechten Einstichkanal dieses Agarmediums im Teströhrchen.

- Nachweis des gelben Pigments von E. casseliflavus: Eine makroskopische Beurteilung des frischen Kolo- niematerials von E. casseliflavus auf einer weißen Oberfläche lassen das gelbe Pigment dieser Spezies erkennen. Ein gelbes Pigment besitzt zwar auch E. mundtii, jedoch ist diese Spezies unbeweglich. Im Gegensatz da$\mathrm{zu}$ ist E. gallinarum zwar beweglich, aber ohne gelbes Pigment; E. faecium und E. faecalis sind weder beweglich, noch gelb pigmentiert.

Enterokokken mit übertragbarer Vancomycin-Resistenz wurden erstmals 1988 zeitgleich in Frankreich und England beschrieben $[45,46]$ und haben sich heute weltweit verbreitet, wenn auch mit unterschiedlichen Häufigkeiten in den einzelnen Ländern. Von den in • Tab. 1 aufgeführten erworbenen Vancomycin-Resistenztypen haben VanA und VanB große klinische Bedeutung erlangt; als Ausnahme können Kliniken in nordeuropäi- schen Ländern (Dänemark, Norwegen, Schweden, Finnland, Island) genannt werden, in denen die Resistenzraten von Enterokokken gegen Glycopeptide gering sind [47].

\section{Resistenzen von Enterokokken und von vanA- oder vanB-positiven E. faecium gegen andere Antibiotika}

Die - Abb. 1 zeigt die Antibiotikaresistenzhäufigkeiten von E.-faecium- und E.-faecalis-Isolaten aus dem stationären Bereich der Krankenhäuser (oben) und aus dem ambulanten Bereich (unten) in Deutschland im Zeitraum von 2008 bis 2011 (Daten aus [24]). E. faecium stellt sich als die Spezies mit dem deutlich breiteren Resistenzspektrum im Vergleich zu E. faecalis dar. Im stationären Bereich war ein Anstieg der Levofloxacin-Resis- 
Tab. 2 Häufigkeit von Resistenzen bei vanA- bzw. vanB-positiven E.-faecium-Isolaten gegen verschiedene Antibiotika (VRE-Einsendungen in 2010 bzw. 2011 an das RKI in Wernigerode)

\begin{tabular}{|c|c|c|c|c|}
\hline \multirow[t]{2}{*}{ Antibiotikum } & \multicolumn{2}{|c|}{ Resistenzhäufigkeiten in 2010, n (\%) } & \multicolumn{2}{|c|}{ Resistenzhäufigkeiten in 2011, n (\%) } \\
\hline & $\begin{array}{l}\text { E. faecium (van } A) \\
n=144\end{array}$ & $\begin{array}{l}\text { E. faecium (vanB) } \\
n=146\end{array}$ & $\begin{array}{l}\text { E. faecium (vanA) } \\
\mathrm{n}=395\end{array}$ & $\begin{array}{l}\text { E. faecium (vanB) } \\
\mathrm{n}=300\end{array}$ \\
\hline PEN & $144(100,0)$ & $146(100,0)$ & $394(99,7)$ & $299(99,7)$ \\
\hline AMP & $144(100,0)$ & $146(100,0)$ & $394(99,7)$ & $299(99,7)$ \\
\hline GEN (Hochres.) & $82(56,9)$ & $62(42,5)$ & $260(65,8)$ & $56(18,7)$ \\
\hline STR (Hochres.) & $70(48,6)$ & $68(46,6)$ & $180(45,6)$ & $125(41,7)$ \\
\hline VAN & $144(100,0)$ & $140(95,9)$ & $395(100,0)$ & $296(98,7)$ \\
\hline TPL & $144(100,0)$ & $0(0,0)$ & $395(100,0)$ & $7(2,3)^{b}$ \\
\hline DAPa & $0(0,0)$ & $0(0,0)$ & $0(0,0)$ & $0(0,0)$ \\
\hline Q/D & $1(0,7)$ & $2(1,4)$ & $4(1,0)$ & $26(8,7)$ \\
\hline $\mathrm{CLI}$ & $141(97,9)$ & $135(92,5)$ & $392(99,2)$ & $281(93,7)$ \\
\hline ERY & $142(98,6)$ & $135(92,5)$ & $393(99,5)$ & $284(94,7)$ \\
\hline CIP (norm. Res.) & $143(99,3)$ & $146(100,0)$ & $393(99,5)$ & $299(99,7)$ \\
\hline CIP (Hochres.) & $141(97,9)$ & $145(99,3)$ & $387(98,5)$ & $292(97,3)$ \\
\hline MFL & $143(99,3)$ & $146(100,0$ & $392(99,2)$ & $298(99,3)$ \\
\hline LNZ & $6(4,2)$ & $1(0,7)$ & $14(3,5)$ & $5(1,7)$ \\
\hline TET & $55(38,2)$ & $12(8,2)$ & $262(66,3)$ & $38(12,7)$ \\
\hline TGC & $3(2,1)$ & $0(0,0)$ & $0(0,0)$ & $0(0,0)$ \\
\hline RAM & $138(95,8)$ & $144(98,6)$ & $385(97,5)$ & $293(97,7)$ \\
\hline SXT & $62(43,1)$ & $38(26,0)$ & $184(46,6)$ & $207(69,0)$ \\
\hline CMPC & $2(1,4)$ & $0(0,0)$ & $1(0,3)$ & $0(0,0)$ \\
\hline
\end{tabular}

PEN Penicillin G, AMP Ampicillin, GEN Gentamicin (Hochresistenz: >128 mg/l), STR Streptomycin (Hochresistenz: >512 mg/l), VANVancomycin, TPL Teicoplanin, DAP Daptomycin, Q/D Quinupristin/Dalfopristin, CLI Clindamycin, ERY Erythromycin, CIP Ciprofloxacin (CIP-Hochresistenz $\geq 32$ mg/l), MFL Moxifloxacin, LNZ Linezolid, TET Tetracyclin, TGC Tigecyclin, RAM Rifampicin, SXT Trimethoprim/Sulfamethoxazol, CMP Chloramphenicol. aln-vivo-Wirksamkeit wird in wissenschaftlicher Literatur kontrovers diskutiert, daher sind in EUCAST keine klinischen MHK-Grenzwerte für DAP bei Enterokokken angegeben, aber der Wildtyp zeigt MHK-Werte von $\leq 4 \mathrm{mg} /$ / (s. Literaturstelle [19]). b7 vanB-positive E.-faecium-Isolate besaßen zusätzlich das vanA-Gen (beide van-Gene in PCR nachweisbar, Stämme sahen phänotypisch anhand der MHK-Werte für VAN und TPL wie VanAStämme aus. 'Keine klinischen MHK-Grenzwerte für CMP bei Enterokokken in EUCAST angegeben, daher wurde der MHK-Breakpoint aus CLSI verwendet: resistent $\geq 32 \mathrm{mg} / \mathrm{l}$ )

tenzhäufigkeit bei $E$. faecium (von 85 auf 95\%) und bei E. faecalis (von 36 auf 49\%) zu beobachten $\bullet$ Abb. 1. Bei den E.-faecium-Isolaten aus diesem Bereich liegen die Resistenzhäufigkeiten gegen Amoxicillin bzw. Ampicillin deutlich über 90\%. Gleichzeitig gehen bei diesen Isolaten die Hochresistenzraten gegen Gentamicin und Streptomycin zurück. Der deutlichere Anstieg der Häufigkeit der Vancomycin- im Vergleich zur TeicoplaninResistenz bei E. faecium aus dem stationären Bereich im Jahr 2011 (ARS-Resistenzhäufigkeiten: Vancomycin 19,1\%; Teicoplanin 6,2\%; [24]) ist ein Hinweis auf das vermehrte Auftreten vanB-positiver Isolate, die nur Vancomycin-resistent sind. Auch die Daten zweier Resistenzstudien der Paul-Ehrlich-Gesellschaft deuten dies bei den E.-faecium-Isolaten an: 2007 ( $n=250$ Isolate) waren 10,8\% Van- comycin- und 6,4\% Teicoplanin-resistent, 2010 ( $\mathrm{n}=301$ Isolate) waren 12,6\% Vancomycin- und 5,0\% Teicoplanin-resistent ([14], Daten für 2010: persönliche Mitteilung M. Kresken, PEG). Im European Antimicrobial Resistance Surveillance Network (EARS-Net) des European Centre for Disease Prevention and Control (ECDC) werden für Deutschland Vancomycin-Resistenzraten von $15 \%$ (2007) bis 8\% (2010) angegeben [48].

Bei E.-faecium- bzw. E.-faecalis-Stämmen im ambulanten Bereich sind geringere Resistenzhäufigkeiten als bei den Isolaten aus dem stationären Bereich gegen die bei ARS ausgewerteten Antibiotika festzustellen. Allerdings stiegen bei E. faecium aus dem ambulanten Bereich die Raten für Ampicillin-, Gentamicin- und Streptomycin-Hochresistenzen und für Chinolon-Resistenzen (Le- vofloxacin, Moxifloxacin) an. Überraschenderweise waren im Jahr 2011 bei den E.-faecium-Isolaten aus dem ambulanten Bereich 18,4\% (67 von 365 Isolaten) Vancomycin- und $6,2 \%$ (21 von 340 Isolaten) Teicoplanin-resistent. Hier liegt aber dennoch vermutlich kein „VRE-Reservoir" außerhalb der Krankenhäuser vor; vielmehr dürfte diese Beobachtung wohl eher auf ehemalige und nun in den ambulanten Bereich entlassene Krankenhauspatienten zurückzuführen sein, die die entsprechenden antibiotikaresistenten Erreger (hier VRE) mitnahmen. In diesem Zusammenhang ist es manchmal nicht ganz einfach, die Trennlinie zwischen stationären und ambulanten $\mathrm{Pa}$ tienten festzulegen.

In - Abb. 2 sind die Häufigkeiten (\%) von Einzelresistenzen und Multiresistenzmustern gegen verschiedene Antibiotika bei E.-faecalis- und E.-faecium-Isolaten aus den Resistenzstudien der PaulEhrlich-Gesellschaft für Chemotherapie der Jahre 1998, 2001, 2004 und 2007 dargestellt. Diese Daten zeigen, dass

a) über $50 \%$ der E.-faecalis-Isolate noch empfindlich gegen alle in den PEGStudien getesteten und klinisch bedeutsamen Antibiotika sind,

b) Multiresistenzen (unter Beteiligung von bis zu 5 Antibiotika) hauptsächlich bei E. faecium zu finden sind und

c) bei E. faecium innerhalb dieses Zeitraumes ein Ampicillin-Resistenzanstieg als Gesamtresistenzrate (Ampicillin-Resistenz allein und gekoppelt mit anderen Antibiotika) von ca. $76 \%$ auf ca. $88 \%$ zu verzeichnen war.

Außerdem haben die Multiresistenzmuster bei E. faecium zwischen 1998 und 2007 deutlich an Vielfalt zugenommen, wobei im Gegenzug der Anteil der sensiblen E.-faecium-Isolate von 15\% (1998) auf $8 \%$ (2007) sank (untere Reihe der grafischen Darstellung). Bei E. faecalis nahm die Häufigkeit von Multiresistenzen in diesem Zeitraum ebenfalls zu (wenn auch in geringerem Umfang), sodass der Anteil der sensiblen Isolate von 66 auf 53\% sank. Dennoch ist die Ampicillin-Gesamtresistenzrate bei E. faecalis (bisher) immer noch sehr günstig; sie lag in den 4 ausgewerteten PEG-Resistenzstudien zwischen 0,9 und $3,3 \%$. 


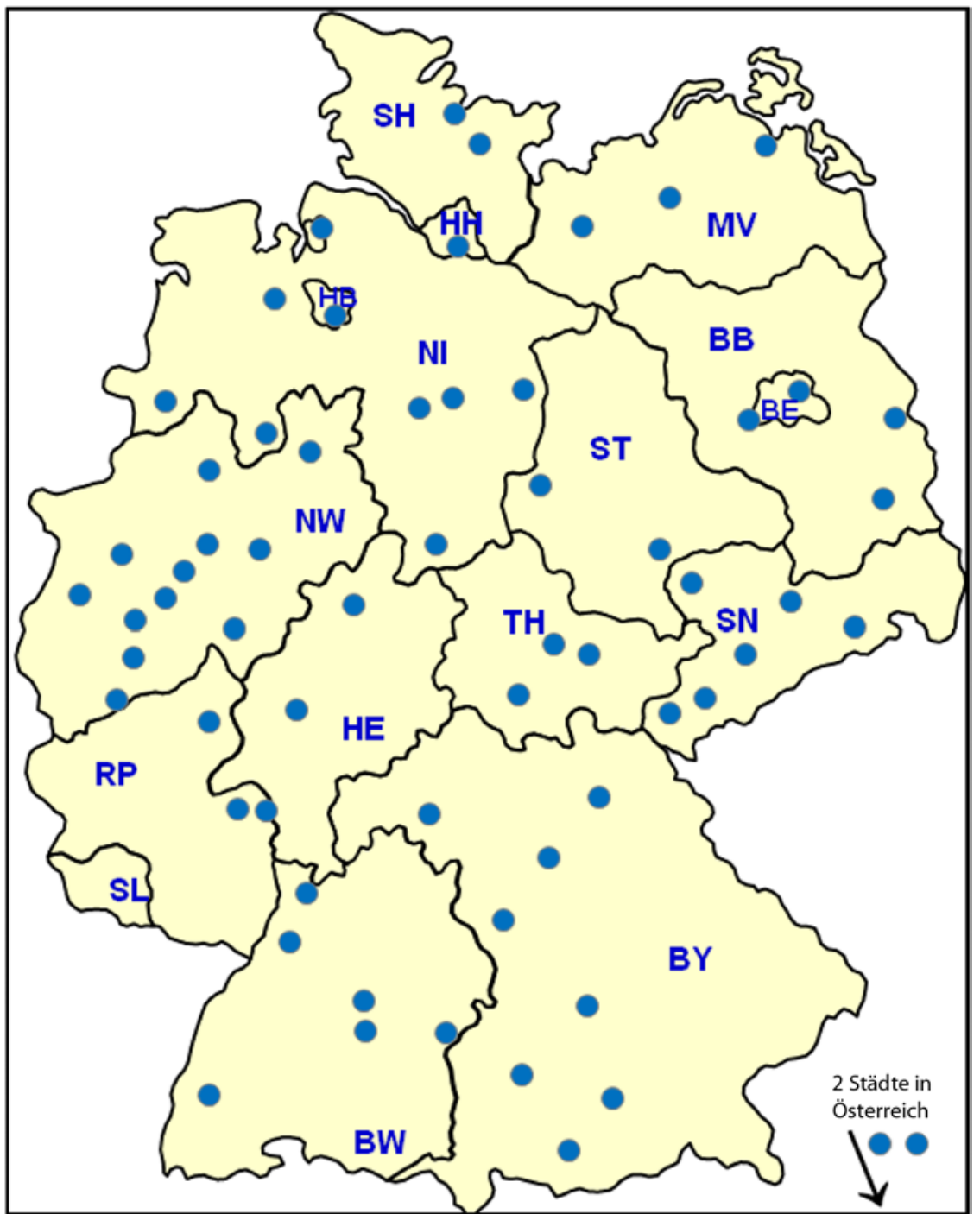

Abb. $3 \Delta$ Geografische Lage der klinisch-mikrobiologischen Labore, die an das RKI in Wernigerode Enterokokkenisolate (meist VRE) mit klinisch-epidemiologischer Fragestellung einsandten (in größeren Städten: mehrere Einsender)

In • Tab. 2 sind die Resistenzhäufigkeiten der im Jahr 2010 und 2011 von den Krankenhäusern und klinisch-mikrobiologischen Laboren nahezu aller Bundesländer (• Abb. 3) an das RKI in Wernigerode eingesandten $v a n A$ - und $v a n B$ positiven E.-faecium-Stämme gegen andere Antibiotika enthalten. Grundlage dieser Auswertung sind die bei EUCAST [19] angegebenen klinischen Grenzwerte für die einzelnen Antibiotika. In Fällen, in denen bei EUCAST keine Grenzwerte angegeben waren, wurde auf andere Resistenzstandards [Clinical Laboratory Standards Institute (CLSI) der USA, $[49,50]$ oder Deutsches Institut für Normung (DIN) [51, 52]] zurückgegriffen. Es zeigte sich, dass besonders die von EU-
CAST zum 01.01.2012 eingeführten neuen Grenzwerte für Vancomycin (resistent $>4 \mathrm{mg} / \mathrm{l}$ ) und Teicoplanin (resistent $>2 \mathrm{mg} / \mathrm{l})$ [19] zu einer deutlich verbesserten Erfassung der vanB-Stämme führt, deren MHK-Werte für Vancomycin aufgrund unterschiedlich starker Expression des vanB-Genclusters (wie oben geschildert) zwischen (1-2-) 4-1000 mg/l schwanken können. Weiterhin zeigte sich, dass E.-faecium-Stämme mit Resistenzen gegen wichtige Reserveantibiotika wie Linezolid und Tigecyclin noch sehr selten auftreten [21, 22, 23]. Überraschend gute In-vitro-Aktivität zeigt das ältere Antibiotikum Chloramphenicol, auch wenn es nur bakteriostatisch wirkt. Außerdem ist schon an der Ampicillin-Resistenz und

an der Ciprofloxacin-Hochresistenz zu erkennen, dass es sich offensichtlich bei nahezu allen VRE-Einsendungen an das RKI in Wernigerode der Jahre 2010 und 2011 um die im nächsten Abschnitt beschriebenen Hospital-assoziierten Stämme von E. faecium handelt.

In - Tab. 3 sind unter (A) die Krankenhausstationen aufgeführt, auf denen bei Patienten vanA- bzw. vanB-positive E.-faecium-Stämme isoliert und die als Enterokokkeneinsendungen der Jahre 2010 und 2011 am RKI in Wernigerode analysiert wurden. Daraus ist zu entnehmen, dass VRE vor allem in der allgemeinen Chirurgie (mit Intensivstation, ITS), in der Inneren Medizin (mit und ohne ITS), in der Hämatologie/Onkologie und in der Urologie/Nephrologie isoliert wurden [in $\bullet$ Tab. 3, unter (A) kursiv hervorgehoben].

Unter (B) dieser Tabelle sind die klinischen Materialien aufgeführt, aus denen die vanA- bzw. vanB-positiven E.-faeci$u m$-Isolate der Enterokokkeneinsendungen in den Jahren 2010 bzw. 2011 an das RKI in Wernigerode stammten: Wundabstriche, andere Abstriche (außer Wundund Rektalabstriche), Venenkatheter und Blutkulturen waren neben den „klassischen" Materialien wie Stuhlproben/ Rektalabstriche und Urine (Mittelstrahlund Katheterurine) die vorrangigen klinischen Materialien.

\section{Auftreten Hospital-assoziierter Stämme von E. faecium}

Die eingangs genannten Risikofaktoren für Enterokokken/VRE-Infektionen oder -Besiedlungen tragen dazu bei, dass in den Krankenhäusern Hospital-assoziierte multiresistente E.-faecium-Stämme auftreten, die sich aufgrund ihrer Umweltpersistenz und von Mängeln in der Basishygiene leicht verbreiten können. Das mittlerweile in verschiedenen deutschen Kliniken beobachtete gehäufte Auftreten Ampicillin/Vancomycin-resistenter E. faecium des vanA- oder vanB-Genotyps sowie Ausbrüche von Infektionen und Besiedlungen mit diesen Erregern konnten im RKI in Wernigerode mittels Pulsfeldgelelektrophorese (PFGE) und Multilocussequenztypisierung (MLST) molekular charakterisiert und die auf- 
Tab. 3 Krankenhausstationen (A) und klinische Materialien (B), aus denen vanA- bzw. vanBpositive E.-faecium-Stämme isoliert wurden (Enterokokkeneinsendungen an das RKI in Wernigerode in 2010 und 2011; ITS, Intensivstation)

\begin{tabular}{|c|c|c|c|c|c|c|c|c|}
\hline \multirow[t]{3}{*}{ (A) Krankenhaus-Station } & \multicolumn{4}{|c|}{ VRE-Einsendungen in 2010} & \multicolumn{4}{|c|}{ VRE-Einsendungen in 2011} \\
\hline & \multicolumn{2}{|c|}{$\begin{array}{l}\text { E. faecium } \\
\text { (vanA) }\end{array}$} & \multicolumn{2}{|c|}{$\begin{array}{l}\text { E. faecium } \\
\text { (vanB) }\end{array}$} & \multicolumn{2}{|c|}{$\begin{array}{l}\text { E. faecium } \\
\text { (vanA) }\end{array}$} & \multicolumn{2}{|c|}{$\begin{array}{l}\text { E. faecium } \\
\text { (vanB) }\end{array}$} \\
\hline & $\mathrm{n}$ & $\%$ & $\mathrm{n}$ & $\%$ & $\mathrm{n}$ & $\%$ & $\mathrm{n}$ & $\%$ \\
\hline Ambulanter Bereich & 2 & 1,39 & 2 & 1,36 & 5 & 1,25 & 8 & 2,65 \\
\hline Reha-Klinik & 12 & 8,33 & 0 & 0,00 & 13 & 3,27 & 0 & 0,00 \\
\hline HNO-Klinik & 0 & 0,00 & 0 & 0,00 & 0 & 0,00 & 1 & 0,33 \\
\hline Anästhesie & 3 & 2,08 & 0 & 0,00 & 1 & 0,25 & 5 & 1,66 \\
\hline Intensivtherapie & 6 & 4,17 & 1 & 0,68 & 25 & 6,28 & 13 & 4,30 \\
\hline Transplantat.-Chirurgie (ITS) & 1 & 0,69 & 1 & 0,68 & 10 & 2,51 & 5 & 1,66 \\
\hline Allgemeine Chirurgie (ITS) & 24 & 16,67 & 38 & 26,03 & 67 & 16,83 & 79 & 26,16 \\
\hline Internistische ITS & 19 & 13,19 & 32 & 21,92 & 57 & 14,32 & 30 & 9,93 \\
\hline Innere Medizin & 21 & 14,58 & 18 & 12,33 & 56 & 14,07 & 43 & 14,24 \\
\hline Chirurgie & 3 & 2,08 & 5 & 3,42 & 8 & 2,01 & 15 & 4,97 \\
\hline Unfallchirurgie & 3 & 2,08 & 4 & 2,74 & 1 & 0,25 & 1 & 0,33 \\
\hline Herzchirurgie & 0 & 0,00 & 2 & 1,37 & 8 & 2,01 & 0 & 0,00 \\
\hline Neurochirurgie/Neurologie & 2 & 1,39 & 1 & 0,68 & 4 & 1,01 & 6 & 1,99 \\
\hline Psychiatrie & 0 & 0,00 & 2 & 1,37 & 0 & 0,00 & 1 & 0,33 \\
\hline Hämatologie/Onkologie & 14 & 9,72 & 10 & 6,85 & 24 & 6,03 & 25 & 8,28 \\
\hline Geriatrie & 6 & 4,17 & 3 & 2,05 & 4 & 1,01 & 6 & 1,99 \\
\hline Urologie/Nephrologie & 5 & 3,47 & 16 & 10,96 & 34 & 8,55 & 13 & 3,31 \\
\hline Dermatologie & 0 & 0,00 & 1 & 0,68 & 0 & 0,00 & 0 & 0,00 \\
\hline Gynäkologie & 0 & 0,00 & 1 & 0,68 & 0 & 0,00 & 2 & 0,66 \\
\hline Pädiatrie/Neonatologie & 8 & 5,55 & 0 & 0,00 & 1 & 0,25 & 1 & 0,33 \\
\hline Dialyse & 0 & 0,00 & 0 & 0,00 & 1 & 0,25 & 0 & 0,00 \\
\hline Orthopädie & 1 & 0,69 & 2 & 1,37 & 1 & 0,25 & 0 & 0,00 \\
\hline Unbekannt & 14 & 9,72 & 8 & 5,48 & 79 & 19,85 & 48 & 15,89 \\
\hline Summe & 144 & 100,00 & 146 & 100,00 & 398 & 100,00 & 302 & 100,00 \\
\hline \multirow[t]{3}{*}{ (B) Klinisches Material } & \multicolumn{4}{|c|}{ VRE-Einsendungen in 2010} & \multicolumn{4}{|c|}{ VRE-Einsendungen in 2011} \\
\hline & \multicolumn{2}{|c|}{$\begin{array}{l}\text { E. faecium } \\
\text { (vanA) }\end{array}$} & \multicolumn{2}{|c|}{$\begin{array}{l}\text { E. faecium } \\
\text { (vanB) }\end{array}$} & \multicolumn{2}{|c|}{$\begin{array}{l}\text { E. faecium } \\
\text { (vanA) }\end{array}$} & \multicolumn{2}{|c|}{$\begin{array}{l}\text { E. faecium } \\
\text { (vanB) }\end{array}$} \\
\hline & $\mathbf{n}$ & $\%$ & $\mathrm{n}$ & $\%$ & $\mathrm{n}$ & $\%$ & $\mathrm{n}$ & $\%$ \\
\hline Biopsie & 1 & 0,69 & 0 & 0,00 & 1 & 0,25 & 0 & 0,00 \\
\hline Blutkultur & 11 & 7,64 & 14 & 9,59 & 20 & 5,03 & 18 & 5,96 \\
\hline Bronchiallavage & 3 & 2,08 & 3 & 2,05 & 4 & 1,00 & 1 & 0,33 \\
\hline Drainage & 3 & 2,08 & 2 & 1,37 & 7 & 1,76 & 8 & 2,65 \\
\hline Venenkatheter & 10 & 6,94 & 7 & 4,79 & 10 & 2,51 & 12 & 3,97 \\
\hline Punktat & 3 & 2,08 & 4 & 2,74 & 7 & 1,76 & 18 & 5,96 \\
\hline Sekret & 3 & 2,08 & 4 & 2,74 & 2 & 0,50 & 3 & 0,99 \\
\hline Sputum & 1 & 0,69 & 1 & 0,68 & 2 & 0,50 & 0 & 0,00 \\
\hline Stuhl/Rektalabstrich & 9 & 6,25 & 9 & 6,16 & 119 & 29,90 & 69 & 22,84 \\
\hline Andere Abstriche & 18 & 12,50 & 8 & 5,48 & 35 & 9,00 & 26 & 8,61 \\
\hline Trachealsekret & 0 & 0,00 & 0 & 0,00 & 4 & 1,01 & 0 & 0,00 \\
\hline Katheterurin & 18 & 12,50 & 9 & 6,16 & 36 & 9,05 & 21 & 6,95 \\
\hline Mittelstrahlurin & 41 & 28,47 & 42 & 28,77 & 88 & 22,11 & 60 & 19,87 \\
\hline Wundabstrich & 16 & 11,11 & 34 & 23,29 & 47 & 11,81 & 37 & 12,25 \\
\hline Unbekannt & 7 & 4,86 & 9 & 6,16 & 15 & 3,77 & 29 & 9,60 \\
\hline Summe & 144 & 100,00 & 146 & 100,00 & 398 & 100,00 & 302 & 100,00 \\
\hline
\end{tabular}

getretenen E.-faecium-Stämme verschiedenen Sequenztypen des klonalen Komplexes CC17 zugeordnet werden [53, 54, $55,56,57]$. Die Selektion dieser HospitalVRE geschieht vermutlich eher auf indirektem Weg - d. h. durch die Unterdrückung der anaeroben Darmflora bei Anwendung von Metronidazol (unwirksam bei Enterokokken) und/oder von in den letzten Jahren in den Kliniken gestiegenen Verbräuchen von Breitspektrum-Cephalosporinen und -Penicillinen [58], die gegen gramnegative Bakterien, nicht aber gegen (Ampicillin-resistente) Enterokokken wirken - und wohl weniger durch den direkten Einsatz von Vancomycin. Krankenhaus-assoziierte VRE verbreiten sich ähnlich wie Methicillin-resistente Staphylococcus aureus (MRSA) auch in verschiedenen Einrichtungen und Bundesländern, z. B. infolge von Patientenverlegungen. Durch horizontalen Gentransfer des vanA-bzw. vanB-Genclusters können innerhalb eines Klinikums auch verschiedene Klone dieser multiresistenten E.-faecium-Stämme existieren [53]. Die Insertionssequenz IS16 und weitere Determinanten ( $\left.e s p, h y l_{\mathrm{Efm}}\right)$ sind geeignete Marker zur Erkennung dieser Hospitalstämme von E. faecium $[59,60,61]$.

\section{Gehäuftes Auftreten vanA- und vanB-positiver E-faecium-Isolate}

Seit Mitte 2003 wurde in deutschen Krankenhäusern die vermehrte Verbreitung Hospital-assoziierter und Virulenzmarker-tragender vanA- und vanB-positiver E.-faecium-Stämme beobachtet, die 2004/2005 auch zu einigen Ausbrüchen von Infektionen und Besiedlungen vor allem in südwestdeutschen Krankenhäusern führten. Gut erkennbar ist diese Situation noch heute am Anstieg der Resistenzhäufigkeiten bei E. faecium gegen Vancomycin von 4 auf $13 \%$ und gegen Teicoplanin von 1 auf 5\% zwischen dem ersten und zweiten Halbjahr 2003 in den VRE-Einsendungen des Labors Dr. Limbach, Heidelberg (• Abb. 4; alle Daten sind patientenbereinigt, d. h. jeweils 1 Isolat pro Patient).

In den Folgejahren wurde im Labor Dr. Limbach eine weitere, stetig steigende Rate an Glycopeptid-resistenten E. faecium in südwestdeutschen Kran- 

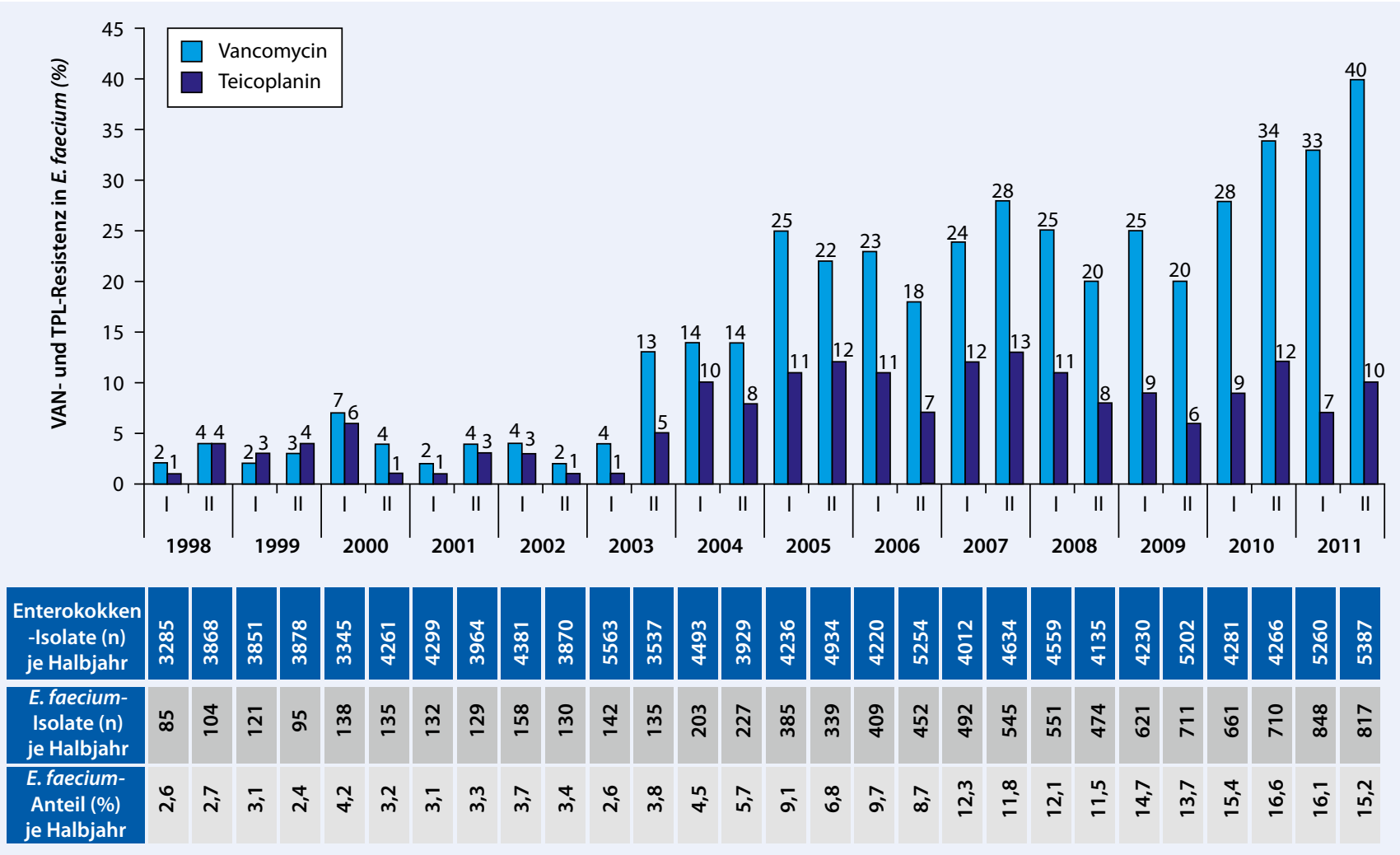

Abb. $4 \Delta$ Häufigkeiten von Vancomycin- bzw. Teicoplanin-Resistenzen (\%) bei E.-faecium-Isolaten aus südwestdeutschen Krankenhäusern 1998 bis 2011 (Daten aus dem Labor Dr. Limbach, Heidelberg; alle Daten sind patientenbereinigt, d. h. 1 Isolat pro Patient)

kenhäusern beobachtet, die (über verschiedene Zwischenstufen) im zweiten Halbjahr 2011 für Vancomycin 40\% (!) erreichte (bei mehr oder weniger gleichbleibender Häufigkeit der TeicoplaninResistenz von ca. $10 \% \pm 3-4 \%$ im Zeitraum 2004 bis 2011). Diese Zahlen sind ein Indiz dafür, dass es in den letzten Jahren zu einem stark gehäuften Auftreten vanB-positiver E.-faecium-Isolate (die nur Vancomycin-resistent sind) in den südwestdeutschen Krankenhäusern gekommen sein muss. Untermauert werden diesen Daten durch den steigenden Anteil der E.-faecium-Isolate in allen Enterokokkeneinsendungen des Labors Dr. Limbach. Dieser erhöhte sich von $2,6 \%$ im 1. Halbjahr 1998 auf über $16 \%$ in den Jahren 2010 und 2011 (unterer Teil der $\mathbf{A b b} .4)$. Die in $\mathbf{A b b .} 4$ zeitlich dargestellten Häufigkeitsverteilungen der Vancomycin- bzw. Teicoplanin-Resistenz von E.-faecium-Isolaten des Labors Dr. Limbach sind vergleichbar mit denen der verschiedenen VRETypen aus den Stammeinsendungen an das RKI in Wernigerode zwischen 2000 und 2011 (• Abb.5). Während vanB-E.faecium-Stämme bis 2003 noch sehr selten auftraten, kam es ab 2004 zu einer immer häufigeren Einsendung dieser Erreger, insbesondere in den Jahren 2009, 2010 und 2011 (• Abb. 5).

Dieses gehäufte Auftreten vanB-positiver Hospital-assoziierter E.-faeciumIsolate war auch bei Patienten innerhalb des betreffenden Krankenhauses verschiedener deutscher Städte vor allem in den Jahren 2010 und 2011 festzustellen. Bei einigen Krankenhäusern wurde die Identität oder nahe Verwandtschaft dieser Erreger mittels der zwar sehr zeit- und kostenintensiven, aber auch sehr genauen SmaI-Makrorestriktionsanalyse (Pulsfeldgelelektrophorese, PFGE; bei Enterokokken nach wie vor als "Goldstandard“ in der Genotypisierung angesehen) im RKI in Wernigerode nachgewiesen.

Die Ursachen für ein vermehrtes Auftreten von bzw. für die ansteigenden Fallzahlen an vanB-positiven E-faecium-Isolaten sind offensichtlich multifaktoriell und könnten die nachfolgenden Punkte einschließen: Seit 2001 werden hohe Verbräuche von Penicillinen mit oder ohne $\beta$-Lactamase-Inhibitor, von Chinolonen und von Erst- und Zweitgenerations-Cephalosporinen in deutschen Krankenhäusern registriert. Diese und auch die stark gestiegenen Verbräuche an Carbapenemen seit 2004 und von Glycopeptiden (vor allem Vancomycin) ab 2008 könnten einen hohen Selektionsdruck auf Enterokokken und VRE bewirkt haben [58]. Außerdem dürfte der seit Jahren bestehende hohe Verbrauch von Drittund Viertgenerations-Cephalosporinen in den Intensivstationen deutscher Krankenhäuser [58] dazu beigetragen haben. Aus der Praxis weiß man, dass die Selektion bestimmter Erreger und die damit verbundenen Resistenzhäufigkeitsanstiege nach einem bestehenden Antibiotikaselektionsdruck erst mit einer gewissen zeitlichen Verzögerung sichtbar werden.

Neben den in den letzten Jahren stark gestiegenen Antibiotikaverbräuchen könnten aber auch methodische Gründe 


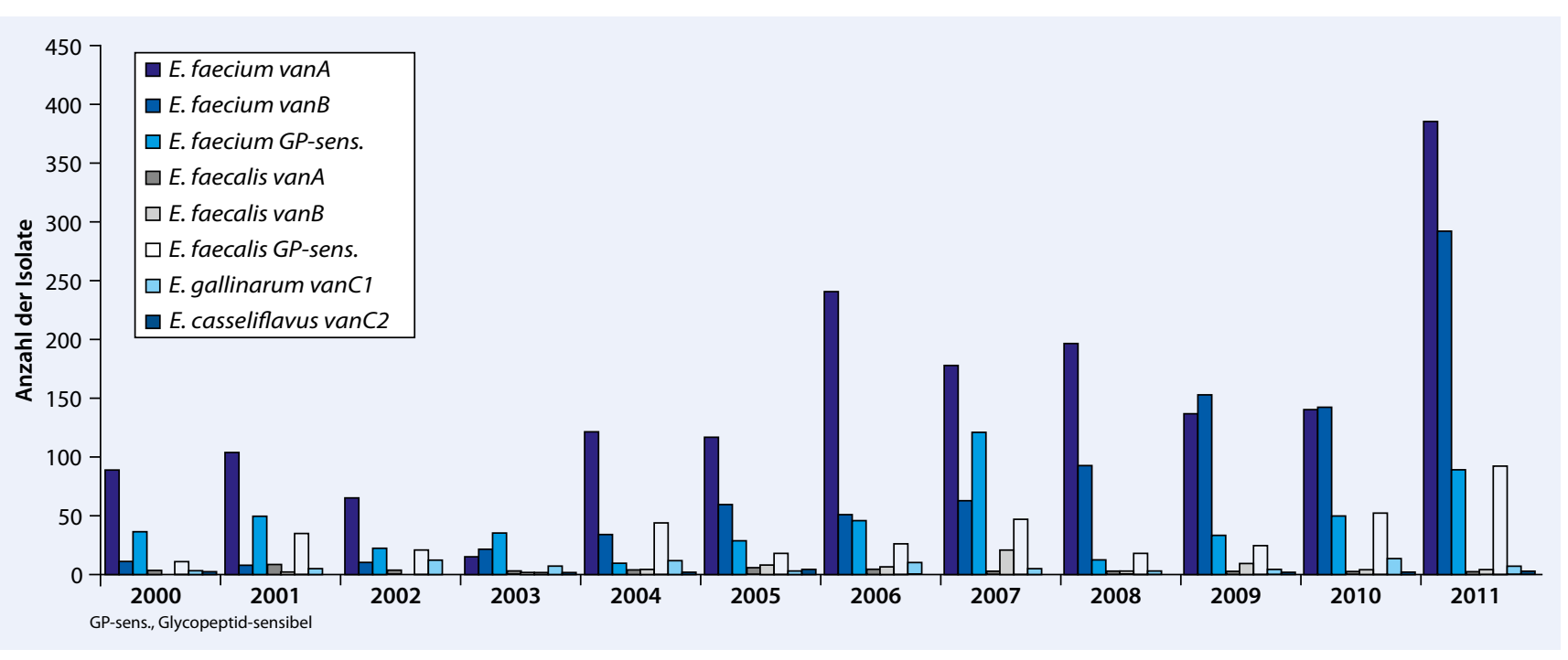

Abb. $5 \Delta$ Anzahl von Isolaten verschiedener Enterokokkenspezies und Vancomycin-Resistenztypen aus Infektionen und Besiedlungen von Patienten in Krankenhäusern (Stammeinsendungen der Jahre 2000 bis 2011 an das RKI in Wernigerode)

eine Rolle spielen. Die kürzlich von EUCAST reduzierten Vancomycin-Grenzwerte [19] und die Bewertungskriterien (Bedeutung der Empfindlichkeitskategorie ,intermediär-resistent" nach CLSI $[49,50])$ haben sicher die Diagnostik und das Erkennen von vanB-VRE mit niedrig exprimierter Vancomycin-Resistenz verbessert. Das prinzipielle Problem der schwachen Resistenzexpression in manchen vanB-positiven E.-faeciumIsolaten ist seit Langem bekannt, wurde aber nicht intensiv bearbeitet bzw. kommuniziert und erfährt erst in letzter Zeit - einhergehend mit steigenden Fallzahlen - eine gewisse Beachtung [62, 63, 64]. Letztlich haben verschiedene diagnostische Hersteller im Vorfeld reagiert und empfehlen für die phänotypische VREVerdachtsdiagnostik ein nährstoffreiches Vollmedium (Brain Heart Infusion, BHI) anstatt des üblichen Mueller-Hinton-Mediums; z. B. ist ein spezielles Etest ${ }^{\circ}$-Protokoll (Etest ${ }^{\circ}$-Makromethode) empfohlen, das zur Erfassung des VanB-Resistenztyps BHI-Agar verwendet, ein höheres Inokulum erfordert und bis zu $48 \mathrm{~h}$ Inkubation vorschlägt (Etest ${ }^{\oplus}$ application sheet for Enterococcus/VRE and vancomycin EAS009, bioMérieux, Nürtingen, Deutschland). Mit Einführung der chromogenen VRE-Selektivagarmedien verschiedener Hersteller lassen sich auch vanB-VRE mit MHK für Vancomycin im Grenzbereich von $\leq 4 \mathrm{mg} / \mathrm{l}$ besser bzw. sensitiver erfassen [65, 66]. Die breitere Anwendung genotypbasierter Nachweisverfahren (vanB-PCR/real-time-PCR, Hybridisierung) umgeht zudem die Probleme der teilweise schwachen Resistenzexpression $[67,68,69]$. Ob das auch in dem mittels PCR-basierten Screeningverfahren identifizierte $v a n B$-Reservoir in intestinalen, kommensalen Bakterien als Ursprung der vanB-bedingten Resistenz in Enterokokken fungieren kann, ist weder qualitativ noch quantitativ einschätzbar [70]. Eine mit der Novellierung des Infektionsschutzgesetzes (IfSG) in Deutschland einhergehende gesteigerte Aufmerksamkeit für multiresistente Erreger (MRE) im Allgemeinen sowie eine veränderte Sachlage hinsichtlich MRE im Speziellen erhöht das Screeningaufkommen in Risikobereichen und bei Risikopatienten, was wiederum zu einem verstärkten Erkennen der Verbreitung der hier diskutierten VRE (insbesondere des VanB-Typs) führt.

Der in Deutschland beobachtete Trend von steigenden VanB-VRE-Raten lässt sich auch in anderen Ländern dokumentieren (Schweden [71], Frankreich [72], Polen, Niederlande), die Ursachen entsprechen vermeintlich den oben diskutierten.

\section{Präventive Maßnahmen zur Verhinderung der Ausbreitung von VRE}

Bereits 1995 wurde in den USA aufgrund der sehr hohen VRE-Inzidenz in amerikanischen Krankenhäusern ein Aufgabenkatalog entworfen, um diese bedrohliche Situation zu entschärfen [73]. Neben der Umsetzung von Hygienemaßnahmen kam es vor allem darauf an, den Selektionsdruck für VRE durch den in den USA sehr breiten Vancomycin-Einsatz rapide zu reduzieren. Dies soll dadurch erreicht werden, dass Vancomycin nur noch dann eingesetzt wird, wenn kein Alternativantibiotikum verwendet werden kann oder wenn die Anwendung des Ersatzmittels mit Blick auf den Therapieerfolg zu unsicher wäre.

Sicherlich ist die VRE-Situation in deutschen Krankenhäusern nicht mit der in den US-amerikanischen Kliniken zu vergleichen, worauf mit einer Stellungnahme bereits 1996 eingegangen wurde [74]. Für den deutschsprachigen Raum sind 2 antiepidemische Maßnahmenkataloge zum Umgang mit VRE-besiedelten oder -infizierten Patienten verfügbar, die in kurzer Form die wichtigsten Maßnahmen und Verhaltensweisen beschreiben: die Konsensusempfehlung Baden-Württemberg [75] und die Publikation von Vonberg et al. [76], die sich beide durch strenge Isolierungsmaßnahmen 
und VRE-Screening in der Vergangenheit zur Eindämmung von VRE-Ausbrüchen in südwestdeutschen Krankenhäusern erfolgreich bewährt haben. Unter dem Eindruck der derzeitigen komplexen VREEpidemiologie - insbesondere des deutlich zunehmenden Auftretens von VanBIsolaten - hat sich eine Expertenrunde zusammengefunden, die die Verhältnismäßigkeit der Maßnahmen [75, 76] unter den gegebenen Situationen in den betroffenen Einrichtungen und anhand der neuen Erkenntnisse zur VRE-Epidemiologie und -Prävalenz derzeit überarbeitet und neu bewertet. Eine der wichtigsten Maßnahmen zur Kontrolle wird immer eine hohe Compliance mit den Basishygienemaßnahmen sein, besonders mit der Händedesinfektion.

\section{Fazit}

Von den beiden klinisch bedeutsamen Enterokokkenspezies $E$. faecalis und $E$. faecium verfügt $E$. faecium über ein breiteres Spektrum an intrinsischen und erworbenen Antibiotikaresistenzen und erlangt dadurch zunehmende Bedeutung als nosokomialer Erreger (wenngleich häufiger Besiedlungen als Infektionen auftreten). Deutliche Unterschiede gibt es bei den erworbenen Resistenzen dieser 2 Spezies, insbesondere hinsichtlich der Resistenzraten gegen Ampicillin und Glycopeptide. Nahezu alle klinischen E.-faecium-Isolate sind resistent gegen Ampicillin. Darüber hinaus existieren in den Krankenhäusern Hospital-assoziierte E.-faecium-Stämme, die sich neben der Ampicillin-Resistenz durch eine Ciprofloxacin-Hochresistenz sowie den Besitz von Virulenzmarkern auszeichnen. Das Reservoir für eine übertragbare Vancomycin-Resistenz (derzeit vor allem VanA und VanB) ist $E$. faecium, wobei in den letzten Jahren Hospital-assoziierte vanB-positive E. faecium besonders in den Risikobereichen von Krankenhäusern zunehmend häufiger auftreten. Günstig sieht die Situation noch bezüglich der Wirksamkeit der Reserveantibiotika Linezolid und Tigecyclin aus, da hier bisher nur selten oder sehr selten Resistenzen festzustellen sind. Die weitere Ausbreitung Kran- kenhaus-assoziierter, multiresistenter E.-faecium-Isolate sollte nicht nur aus Krankenhaus-hygienischer Sicht verhindert werden (insbesondere wenn Resistenzen gegen Reserveantibiotika vorliegen), sondern auch, um die Übertragung der Multi- und Vancomycin-Resistenz innerhalb von E. faecium sowie auf E. faecalis, Staphylococcus aureus oder auf andere klinisch bedeutsame grampositive Bakterien zu vermeiden. Dazu ist neben einer hohen Compliance mit Basishygienemaßnahmen, dem frühzeitigen Erkennen und der Genotypisierung solcher Isolate (z. B. mittels SmalMakrorestriktionsanalyse) sowie der Einleitung entsprechender antiepidemischer Hygienemaßnahmen bei ihrem ersten Auftreten bei Krankenhauspatienten vor allem der überlegte Einsatz von Antibiotika mit fehlender Wirksamkeit gegen Enterokokken (mit und ohne Ampicillin-Resistenz) sowie von Glycopeptiden in den Kliniken von entscheidender Bedeutung.

\section{Korrespondenzadresse}

\section{Dr. I. Klare}

Nationales Referenzzentrum für Staphylokokken und Enterokokken, Robert Koch-Institut

Burgstr. 37, 38855 Wernigerode i.klare@rki.de

Danksagungen. Wir möchten allen Einsendern für die Bereitstellung von Enterokokkenisolaten danken.

Interessenkonflikt. Der korrespondierende Autor gibt für sich und seine Koautoren an, dass kein Interessenkonflikt besteht.

\section{Literatur}

1. Schleifer KH, Kilpper-Balz R (1984) Transfer of Streptoccus faecalis and Streptococcus faecium to the genus Enterococcus nom. rev. as Enterococcus faecalis comb. nov. and Enterococcus faecium comb. nov. Int J Syst Bacteriol 34:31-34

2. Köhler W (2007) The present state of species with the genera Streptococcus and Enterococcus. Int J Med Microbiol 297:133-150

3. Fisher K, Phillips C (2009) The ecology, epidemiology, and virulence of Enterococcus. Microbiology 155:1749-1757

4. Waar K, van der Mei HC, Harmsen HJ et al (2002) Adhesion to bile drain materials and physicochemical surface properties of Enterococcus faecalis strains grown in the presence of bile. Appl Environ Microbiol 68:3855-3858
5. Maki DG, Agger WA (1998) Enterococcal bacteremia: clinical features, the risk of endocarditis, and management. Medicine 67:246-269

6. Landry SL, Kaiser DL, Wenzel RP (1989) Hospital stay and mortality attributed to no- socomial enterococcal bacteremia: a controlled study. Am J Infect Control 17:323-329

7. DiazGranados CA, Zimmer SM, Klein M, Jernigan JA (2005) Comparison of mortality associated with vancomycin-resistant and vancomycinsusceptible enterococcal bloodstream infections: a meta-analysis. Clin Infect Dis 41:327-333

8. Butler AM, Olsen MA, Merz LR et al (2010) Attributable costs of enterococcal bloodstream infections in a nonsurgical hospital cohort. Infect Control Hosp Epidemiol 31:28-35

9. Crank VW, Scheetz MH, Brielmaier B et al (2010) Comparison of outcomes from daptomycin or linezolid treatment for vancomycin-resistant enterococcal bloodstream infection: a retrospective, multicenter, cohort study. Clin Ther 32:17131719

10. Conde-Estévez D, Grau S, Albanell J et al (2011) Clinical characteristics and outcomes of patients with vancomycin-susceptible Enterococcus faecalis and Enterococcus faecium bacteraemia in cancer patients. Eur J Clin Microbiol Infect Dis 30:103-108

11. Peel T, Cheng AC, Spelman T et al (2012) Differing risk factors for vancomycin-resistant and vancomycin-sensitive enterococcal bacteraemia. Clin Microbiol Infect 18:388-394

12. Taur Y, Xavier JB, Lipuma L et al (2012) Intestinal domination and the risk of bacteremia in patients undergoing allogeneic hematopoietic stem cell transplantation. Clin Infect Dis. DOI: $10.1093 /$ cid/ cis580

13. Weinstock DM, Conlon M, lovino C et al (2007) Colonization, bloodstream infection, and mortality caused by vancomycin-resistant enterococcus early after allogeneic hematopoietic stem cell transplant. Biol Blood Marrow Transplant 13:615621

14. Kresken M, Hafner D, Schmitz FJ, Wichelhaus TA für die Studiengruppe PEG-Resistenzstudie: Resistenzsituation bei klinisch wichtigen Infektionserregern gegenüber Antibiotika in Deutschland und im mitteleuropäischen Raum. Bericht über die Ergebnisse einer multizentrischen Studie der Arbeitsgemeinschaft Empfindlichkeitsprüfungen \& Resistenz der Paul-Ehrlich-Gesellschaft für Chemotherapie e.V. aus den Jahren 1998/2001/2004/2007. Online: http://www.p-e-g org/ag_resistenz/main.htm

15. Kritsotakis El, Christidou A, Roumbelaki M et al (2008) The dynamic relationship between antibiotic use and the incidence of vancomycin-resistant Enterococcus: time-series modelling of 7-year surveillance data in a tertiary-care hospital. Clin Microbiol Infect 14:747-754

16. Kolar M, Urbanek K, Vagnerova I, Koukalova D (2006) The influence of antibiotic use on the occurrence of vancomycin-resistant enterococci. J Clin Pharm Ther 31:67-72

17. Stille W, Brodt H-R, Groll AH, Just-Nübling G (2005) Antbiotikatherapie. Klinik und Praxis der antiinfektiösen Behandlung (Stille W, Hrsg), 11. Aufl. Schattauer, Stuttgart, S 413-414

18. Werner G, Fleige C, Ewert B et al (2010) High-level ciprofloxacin resistance among hospital-adapted Enterococcus faecium (CC17). Int J Antimicrob Agents 35:119-125 
19. EUCAST, European Committee on Antimicrobial Susceptibility Testing (2012) Breakpoint tables for interpretation of MICs and zone diameters, version 2.0, valid from 2012-01-01. Online: http:// www.eucast.org/clinical_breakpoints/

20. Wiedemann B (2008) Wirksamkeit von Daptomycin bei grampositiven Erregern. Chemother J 17:2-9

21. Halle E, Padberg J, Rosseau S et al (2004) Linezolid-resistant Enterococcus faecium and Enterococcus faecalis isolated from a septic patient: report of first isolates in Germany. Infection 32:182-183

22. Seedat J, Zick G, Klare I et al (2006) Rapid emergence of resistance to linezolid during linezolid therapy of an Enterococcus faecium infection. Antimicrob Agents Chemother 50:4217-4219

23. Werner G, Gfrörer S, Fleige C et al (2008) Tigecycline-resistant Enterococcus faecalis strain isolated from a German ICU patient. J Antimicrob Chemother 61:1182-1183

24. ARS, Antibiotika-Resistenz-Surveillance in Deutschland, Datenbank: Resistenzübersicht $E$. faecium, E. faecalis; stationärer und ambulanter Bereich, 2008-2011. https://ars.rki.de/

25. Dutka-Malen S, Evers S, Courvalin P (1995) Detection of glycopeptide resistance genotypes and identification to the species level of clinically relevant enterococci by PCR. J Clin Microbiol 33:24-27

26. Courvalin P (2005) Genetics of glycopeptide resistance in gram-positive pathogens. Int J Med Microbiol 294:479-486

27. Courvalin $P$ (2006) Vancomycin resistance in gram-positive cocci. Clin Infect Dis 42(Suppl 1):S25-S34

28. Werner G (2012) Current trends of emergence and spread of vancomycin-resistant enterococci. In: Pana M (Hrsg) Antibiotic resistant bacteria - a continuous challenge in the new millennium. in tech; S 1-52. Online: http://www.intechopen. com/books/antibiotic-resistant-bacteria-a-continuous-challenge-in-the-new-millennium/current-trends-of-emergence-and-spread-of-vancomycin-resistant-enterococci

29. Noble WC, Virani Z, Cree RGA (1992) Co-transfer of vancomycin and other resistance genes from $\mathrm{En}$ terococcus faecalis NCTC 12201 to Staphylococcus aureus. FEMS Microbiol Lett 93:195-198

30. Centers for Disease Control (2002) Staphylococcus aureus resistant to vancomycin - United States. MMWR Morb Mortal Wkly Rep 51:565-567

31. Poyart C, Pierre C, Quesne G et al (1997) Emergence of vancomycin resistance in the genus Streptococcus: characterization of a vanB transferable determinant in Streptococcus bovis. Antimicrob Agents Chemother 41:24-29

32. Lebreton F, Depardieu F, Bourdon N et al (2011) DAla-D-Ser VanN-type transferable vancomycin resistance in Enterococcus faecium. Antimicrob Agents Chemother 55:4606-4612

33. Toye B, Shymanski J, Bobrowska M et al (1997) Clinical and epidemiological significance of enterococci intrinsically resistant to vancomycin (possessing the van ( genotype). J Clin Microbiol 35:3166-3170

34. Choi S-H, Lee S-O, Kim TH et al (2004) Clinical features and outcomes of bacteremia caused by Enterococcus casseliflavus and Enterococcus gallinarum: analysis of 56 cases. Clin Infect Dis 38:5361

35. Tschudin Sutter S, Frei R, Dangel M et al (2010) Not all patients with vancomycin-resistant enterococci need to be isolated. Clin Infect Dis 51:678683
36. Naser SM, Vancanneyt M, Hoste B et al (2006) Reclassification of Enterococcus flavescens Pompei et al. 1992 as a later synonym of Enterococcus casseliflavus (ex Vaughan et al. 1979) Collins et al. 1984 and Enterococcus saccharominimus Vancanneyt et al. 2004 as a later synonym of Enterococcus italicus Fortina et al. 2004. Int J Syst Evol Microbiol 56:413-416

37. Eigner U, Weizenegger M, Fahr AM, Witte W (2005) Evaluation of a rapid direct assay for identification of bacteria and the mecA and van genes from positive-testing blood cultures. J Clin Microbiol 43:5256-5262

38. Depardieu F, Perichon B, Courvalin P (2004) Detection of the van alphabet and identification of enterococci and staphylococci at the species level by multiplex PCR. J Clin Microbiol 42:5857-5860

39. Klare I, Werner G, Witte W (2010) Enterokokken mit Vancomycin-Resistenz in deutschen Krankenhäusern 2008/2009. Epidemiol Bull 44:427-436

40. Patel R, Piper KE, Rouse MS et al (1998) Determination of $16 \mathrm{~S}$ rRNA sequences of enterococci and application to species identification of nonmotile Enterococcus gallinarum isolates. J Clin Microbiol 36:3399-3407

41. Williams AM, Rodrigues UM, Collins MD (1991) Intrageneric relationships of enterococci as determined by reverse transcriptase sequencing of small-subunit rRNA. Res Microbiol 142:67-74

42. Foglia G, Del Grosso M, Vignaroli C et al (2003) Molecular analysis of Tn 1546-like elements mediating high-level vancomycin resistance in Enterococcus gallinarum. J Antimicrob Chemother 52:772-775

43. Schooneveldt JM, Marriott RK, Nimmo GR (2000) Detection of a vanB determinant in Enterococcus gallinarum in Australia. J Clin Microbiol 38:3902

44. Haenni M, Saras E, Châtre P et al (2009) vanA in Enterococcus faecium, Enterococcus faecalis, and Enterococcus casseliflavus detected in French cattle. Foodborne Pathog Dis 6:1107-1111

45. Leclercq R, Derlot E, Duval J, Courvalin P (1988) Plasmid-mediated resistance to vancomycin and teicoplanin in Enterococcus faecium. N Engl J Med 319:157-161

46. Uttley AH, Collins CH, Naidoo J, George RC (1988) Vancomycin-resistant enterococci. Lancet 1:57-58

47. Werner G, Coque TM, Hammerum AM et al (2008) Emergence and spread of vancomycin resistance among enterococci in Europe. Euro Surveill 13:pii=19046. http://www.eurosurveillance.org/ ViewArticle.aspx?Articleld $=19046$

48. ECDC, European Centre for Disease Prevention and Control: European Antimicrobial Resistance Surveillance Network (EARS-Net) 2011 (resistance data for 2010). http://ecdc.europa.eu/en/activities/diseaseprogrammes/ARHAI/Presentations2011Warsaw/ARHAl-networks-meeting_plenary-session-two-2-Oler-Heuer.pdf

49. CLSI, Clinical Laboratory Standards Institute (2012) Performance standards for antimicrobial susceptibility testing - Twenty-second informational supplement, M100-S22 (Vol. 32, No. 3)

50. CLSI, Clinical Laboratory Standards Institute (2012) Methods for dilution antimicrobial susceptibility tests for bacteria that grow aerobically; approved standard - Ninth edition

51. DIN, Deutsches Institut für Normung e.V. (2004) DIN 58940-8: Empfindlichkeitsprüfung von mikrobiellen Krankheitserregern gegen Chemotherapeutika, Teil 8: Mikrodilution. In: DIN-Taschenbuch 222 - Medizinische Mikrobiologie und Immunologie, Diagnostische Verfahren. Beuth, Berlin, S 342-353
52. DIN, Deutsches Institut für Normung e.V. (2004) DIN 58940-4: Empfindlichkeitsprüfung von mikrobiellen Krankheitserregern gegen Chemotherapeutika, Teil 4: Bewertungsstufen für die minimale Hemmkonzentration, Beiblatt 1: MHKGrenzwerte von antibakteriellen Wirkstoffen. In: DIN-Taschenbuch 222 - Medizinische Mikrobiologie und Immunologie, Diagnostische Verfahren. Beuth, Berlin, S 307-323

53. Klare I, Konstabel C, Mueller-Bertling S et al (2005) Spread of ampicillin/vancomycin-resistant Enterococcus faecium of the epidemic-virulent clonal complex-17 carrying the genes esp and hyl in German hospitals. Eur J Clin Microbiol Infect Dis 24:815-825

54. Willems RJ, Top J, Santen M van et al (2005) Global spread of vancomycin-resistant Enterococcus faecium from distinct nosocomial genetic complex. Emerg Infect Dis 11:821-828

55. Willems RJL, Bonten, Marc JM (2007) Glycopeptide-resistant enterococci: deciphering virulence, resistance and epidemicity. Curr Opin Infect Dis 20:384-390

56. Top J, Willems R, Bonten M (2008) Emergence of CC17 Enterococcus faecium: from commensal to hospital-adapted pathogen. FEMS Immunol Med Microbiol 52:297-308

57. Willems RJ, Schaik W van (2009) Transition of Enterococcus faecium from commensal organism to nosocomial pathogen. Future Microbiol 4:1125-1135

58. With K de, Kern WV, Meyer E (2011) Kapitel 2.2: Antibiotikaverbrauch im Krankenhaus. In: Bundesamt für Verbraucherschutz und Lebensmittelsicherheit/Paul-Ehrlich-Gesellschaft für Chemotherapie e.V./Infektiologie Freiburg (Hrsg) GERMAP 2010 - Antibiotika-Resistenz und -Verbrauch. Bericht über den Antibiotikaverbrauch und die Verbreitung von Antibiotikaresistenzen in der Human- und Veterinärmedizin in Deutschland. Antiinfectives Intelligence Gesellschaft für klinisch-mikrobiologische Forschung und Kommunikation $\mathrm{mbH}$, Rheinbach, 1. Aufl.

59. Willems RJ, Homan W, Top J et al (2001) Variant esp gene as a marker of a distinct genetic lineage of vancomycin-resistant Enterococcus faecium spreading in hospitals. Lancet 357:853-855

60. Rice LB, Carias L, Rudin S et al (2003) A potential virulence gene, $h y l_{\text {Efm, }}$ predominates in Enterococcus faecium of clinical origin. J Infect Dis 187:508-512

61. Werner G, Fleige C, Geringer U et al (2011) IS element IS16 as a molecular screening tool to identify hospital-associated strains of Enterococcus faecium. BMC Infect Dis 11:80

62. Adler H, Oezcan S, Frei R (2010) Vancomycin-resistant enterococci of vanB genotype may pose problems for screening with highly selective media. J Clin Microbiol 48:2323

63. Raponi G, Ghezzi MC, Gherardi G et al (2010) Analysis of methods commonly used for glycopeptide and oxazolidinone susceptibility testing in Enterococcus faecium isolates. J Med Microbiol 59:672-678

64. Rathe M, Kristensen L, Ellermann-Eriksen S et al (2010) Vancomycin-resistant Enterococcus spp.: validation of susceptibility testing and in vitro activity of vancomycin, linezolid, tigecycline and daptomycin. Acta Pathol Microbiol Immunol Scand 118:66-73 
65. Grabsch EA, Ghaly-Derias S, Gao W, Howden BP (2008). Comparative study of selective chromogenic (chromID VRE) and bile esculin agars for isolation and identification of vanB-containing vancomycin-resistant enterococci from feces and rectal swabs. J Clin Microbiol 46:4034-4036

66. Klare I, Fleige C, Geringer U et al (2012) Performance of three chromogenic VRE screening agars, two Etest vancomycin protocols and different microdilution methods in detecting vanB genotype Enterococcus faecium with varying levels of vancomycin expression. Diagn Microbiol Infect Dis. 74:171-176

67. Stamper PD, Cai M, Lema C et al (2007) Comparison of the BD GeneOhm VanR Assay to culture for identification of vancomycin-resistant enterococci in rectal and stool specimens. J Clin Microbiol 45:3360-3365

68. Young HL, Ballard SA, Roffey P, Grayson ML (2007) Direct detection of vanB2 using the Roche LightCycler van $A / B$ detection assay to indicate vancomycin-resistant enterococcal carriage - sensitive but not specific. J Antimicrob Chemother 59:809810

69. Werner G, Serr A, Schütt S et al (2011) Comparison of direct cultivation on a selective solid medium, polymerase chain reaction from an enrichment broth, and the BD GeneOhm ${ }^{\mathrm{TM}}$ VanR Assay for identification of vancomycin-resistant enterococci in screening specimens. Diagn Microbiol Infect Dis 70:512-521

70. Ballard SA, Pertile KK, Lim M et al (2005) Molecular characterization of vanB elements in naturally occurring gut anaerobes. Antimicrob Agents Chemother 49:1688-1694

71. Söderblom T, Aspevall O, Erntell M et al (2010) Alarming spread of vancomycin resistant enterococci in Sweden since 2007. Euro Surveill; 15:pii=19620. http://www.eurosurveillance.org/ ViewArticle.aspx?Articleld $=19620$

72. Bourdon N, Fines-Guyon M, Thiolet JM et al (2011) Changing trends in vancomycin-resistant enterococci in French hospitals, 2001-2008. J Antimicrob Chemother 66:713-721

73. CDC, Centers for Disease Control and Prevention (1995) Recommendations for preventing the spread of vancomycin resistance. Recommendations of the Hospital Infection Control Practices Advisory Committee (HICPAC). MMWR Morb Mortal Wkly Rep 44(RR-12):1-13

74. Witte W, Heuck D, Klare I, Kniehl E (1996) Stellung-

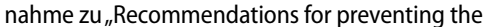
spread of vancomycin resistance" (HICPAC). Hospital Infection Control Practices, Advisory Committee, MMWR, Vol.:44, No. RR-12. Mikrobiologe 6:134-136

75. Baum H von, Dettenhofer M, Fahr A-M et al (2006) Konsensusempfehlung Baden-Württemberg: Umgang mit Patienten mit Glykopeptid-resistenten Enterokokken (GRE)/Vancomycin-resistenten Enterokokken (VRE). Hyg Med 31:30-32. Online: http://www.mre-rhein-main.de/downloads/VRE Konsensus_BW.pdf

76. Vonberg RP, Chaberny IF, Kola A et al (2007) Prävention und Kontrolle der Ausbreitung von Vancomycin-resistenten Enterokokken. Ergebnisse eines Workshops der Deutschen Gesellschaft für Hygiene und Mikrobiologie. Anaesthesist 56:151157

\section{Von Arthritis bis Zahn- vorsorgeuntersuchung: Neue Daten und Trends zu Gesundheit und Lebens- situation in Deutschland}

Knapp 75\% der Männer und 69\% der Frauen schätzen ihre Gesundheit als "ssehr gut" oder "gut" ein. Asthma nimmt bei Frauen und Männern zu. Ein Drittel der Männer und ein Fünftel der Frauen trinkt zu viel Alkohol. Die Inanspruchnahme von Zahnvorsorgeuntersuchungen ist im mittleren Lebensalter zwischen 30 und 64 Jahren am höchsten. $6 \%$ der Erwachsenen waren in einem Jahr an mehr als 50 Tagen krank. Frauen aus Baden-Württemberg leiden seltener an Diabetes.

Dies sind einige Ergebnisse der neuen Telefonbefragung des RKI mit insgesamt 22.050 Teilnehmern aus allen Regionen. Die Daten geben ein umfassendes Bild des Gesundheitszustands, der Einflussfaktoren auf die Gesundheit sowie der Inanspruchnahme von Leistungen des Gesundheitssystems. Durch den Vergleich mit den Ergebnissen früherer Gesundheitsbefragungen 2003 und 2009 lassen sich Trends einschätzen. Die Daten ermöglichen auch den Vergleich zwischen Baden-Württemberg, Bayern, Nordrhein-Westfalen und Regionen, in denen jeweils einige kleinere Länder zusammengefasst sind.

Die Befragung GEDA ("Gesundheit in

Deutschland aktuell") wird regelmäßig durchgeführt. Sie besteht aus einem konstanten Kernbereich und flexiblen Themen zu aktuellen Fragestellungen. Bei der aktuellen Befragung beantworteten Männer und Frauen im Alter ab 18 Jahren zwischen September 2009 und Juli 2010 insgesamt etwa 200 Fragen.

Die Ergebnisse der 33 Themen (Indikatoren) werden übersichtlich in Faktenblättern dargestellt. Jedes Faktenblatt, von Arthritis bis Zahnvorsorgeuntersuchung, ist identisch gegliedert in Einleitung, Indikator, Kernaussagen, Ergebnisbewertung, Häufigkeitsverteilung (nach Alter, Bildungsgruppe und Geschlecht) sowie regionale Verteilung. Themen, die besonders interessieren, sind dadurch schnell zugänglich. Der GEDA-2010-Bericht kann kostenlos beim RKI bestellt werden und ist auf den RKI-Internetseiten als Pdf-Datei abrufbar. Zusätzlich können die Originaldaten für wissenschaftliche Auswertungen als so genannter Public Use File angefordert werden.
Im Internet, im Informationssystem der Gesundheitsberichterstattung des Bundes, sind auch die wichtigsten Kennziffern von GEDA 2009 und 2010 in gestaltbaren Tabellen zu finden. Diese Tabellen können hinsichtlich der Gliederungstiefe (Altersgruppen, Geschlecht, Bildungsstatus, Region) verändert und heruntergeladen werden. Das Informationssystem umfasst über GEDA hinaus mehr als 100 Datenquellen der Statistischen Ämter des Bundes und der Länder, des RKI und zahlreicher weiterer Institutionen aus dem Gesundheitsbereich und ist die zentrale Informationsquelle für gesundheitsbezogene Fragestellungen. Die Gesundheitsberichterstattung des Bundes ist eine gemeinsame Aufgabe des RKI und des Statistischen Bundesamtes (Destatis). Die Daten des Telefonsurveys GEDA ergänzen die Ergebnisse aus DEGS, der „Studie zur Gesundheit Erwachsener in Deutschland", deren erste Ergebnisse im Juni 2012 vorgestellt wurden. Bei GEDA liegt der Schwerpunkt in der Bereitstellung aktueller Gesundheitsdaten, der Möglichkeit der Regionalisierung von Daten und der Analyse zeitlicher Trends. DEGS ist dagegen ein Untersuchungssurvey: neben Befragungen gibt es auch körperliche Untersuchungen und Tests sowie Laboruntersuchungen von Blut- und Urinproben. Bei DEGS werden die Teilnehmer auch in den Folge-Untersuchungen befragt, das ermöglicht über die Jahre "Längsschnitt-Analysen", die für die Ursachenanalyse von Erkrankungen wichtig sind. Zusammen mit der Kindergesundheitsstudie KiGGS bilden GEDA und DEGS das Gesundheitsmonitoring, mit dem das RKI im Auftrag des Bundesgesundheitsministeriums die Gesundheit der Bevölkerung kontinuierlich untersucht.

Bestelladresse:

gbe@rki.de und

030-187543400

Internet-Informationen:

www.rki.de/geda

www.gbe-bund.de

Quelle:

Robert Koch-Institut, Berlin, www.rki.de 